\title{
Dynamic range and sensitivity requirements of satellite ocean color sensors: learning from the past
}

\author{
Chuanmin $\mathrm{Hu},{ }^{1, *}$ Lian Feng, ${ }^{1,2}$ Zhongping Lee, ${ }^{3}$ Curtiss O. Davis, ${ }^{4}$ \\ Antonio Mannino, ${ }^{5}$ Charles R. McClain, ${ }^{5}$ and Bryan A. Franz ${ }^{5}$ \\ ${ }^{1}$ University of South Florida, College of Marine Science, 140 Seventh Avenue, South, \\ St. Petersburg, Florida 33701, USA \\ ${ }^{2}$ Wuhan University, State Key Laboratory of Information Engineering in Surveying, \\ Mapping and Remote Sensing, Wuhan 430079, China \\ ${ }^{3}$ University of Massachusetts, Boston, Department of Environmental, Earth and Ocean Sciences, \\ Boston, Massachusetts 02125, USA \\ ${ }^{4}$ College of Earth, Ocean and Atmospheric Sciences, Oregon State University, Corvallis, Oregon 97331, USA \\ ${ }^{5}$ NASA Goddard Space Flight Center, Greenbelt, Maryland 20771, USA \\ ${ }^{*}$ Corresponding author: hu@ marine.usf.edu
}

Received 11 April 2012; revised 14 June 2012; accepted 10 July 2012;

posted 23 July 2012 (Doc. ID 166494); published 24 August 2012

\begin{abstract}
Sensor design and mission planning for satellite ocean color measurements requires careful consideration of the signal dynamic range and sensitivity (specifically here signal-to-noise ratio or SNR) so that small changes of ocean properties (e.g., surface chlorophyll-a concentrations or Chl) can be quantified while most measurements are not saturated. Past and current sensors used different signal levels, formats, and conventions to specify these critical parameters, making it difficult to make cross-sensor comparisons or to establish standards for future sensor design. The goal of this study is to quantify these parameters under uniform conditions for widely used past and current sensors in order to provide a reference for the design of future ocean color radiometers. Using measurements from the Moderate Resolution Imaging Spectroradiometer onboard the Aqua satellite (MODISA) under various solar zenith angles (SZAs), typical $\left(L_{\text {typical }}\right)$ and maximum $\left(L_{\max }\right)$ at-sensor radiances from the visible to the shortwave IR were determined. The $L_{\text {typical }}$ values at an SZA of $45^{\circ}$ were used as constraints to calculate SNRs of 10 multiband sensors at the same $L_{\text {typical }}$ radiance input and 2 hyperspectral sensors at a similar radiance input. The calculations were based on clear-water scenes with an objective method of selecting pixels with minimal cross-pixel variations to assure target homogeneity. Among the widely used ocean color sensors that have routine global coverage, MODISA ocean bands $(1 \mathrm{~km})$ showed 2-4 times higher SNRs than the Sea-viewing Wide Field-of-view Sensor (SeaWiFS) $(1 \mathrm{~km})$ and comparable SNRs to the Medium Resolution Imaging Spectrometer (MERIS)-RR (reduced resolution, $1.2 \mathrm{~km}$ ), leading to different levels of precision in the retrieved Chl data product. MERIS-FR (full resolution, $300 \mathrm{~m}$ ) showed SNRs lower than MODISA and MERIS-RR with the gain in spatial resolution. SNRs of all MODISA ocean bands and SeaWiFS bands (except the SeaWiFS near-IR bands) exceeded those from prelaunch sensor specifications after adjusting the input radiance to $L_{\text {typical }}$. The tabulated $L_{\text {typical }}, L_{\max }$, and SNRs of the various multiband and hyperspectral sensors under the same or similar radiance input provide references to compare sensor performance in product precision and to help design future missions such as the Geostationary Coastal and Air Pollution Events (GEO-CAPE) mission and the Pre-Aerosol-Clouds-Ecosystems (PACE) mission currently being planned by the U.S. National Aeronautics and Space Administration (NASA). () 2012 Optical Society of America

OCIS codes: $\quad 280.0280,280.4788,010.4450$.
\end{abstract}




\section{Introduction}

In the past several decades, satellite ocean color radiometry has evolved from the proof-of-concept Coastal Zone Color Scanner (CZCS, 1978-1986) to modern instruments such as the Sea-viewing Wide Field-of-view Sensor (SeaWiFS, 1997-2010) and the Moderate Resolution Imaging Spectroradiometer (MODIS, 1999-present for Terra and 2002-present for Aqua). Added to this suite of optical measurements were the Medium Resolution Imaging Spectrometer (MERIS, 2002-2012), the Ocean Color Monitor (OCM-1, 1999-present; OCM-2, 2009present), and the most recent Geostationary Ocean Color Imager (GOCI, 2010-present). These frequent and synoptic observations of the global ocean provided unprecedented opportunities to study the ocean's biogeochemistry, trace ocean circulation, monitor harmful algal blooms (HABs) and pollutions such as oil spills, document coastal water quality changes, and help make management decisions on coral reef ecosystems and fisheries.

To continue these observations without data gaps, future satellite ocean color missions are being planned by the U.S. National Aeronautics and Space
Administration (NASA), the European Space Agency (ESA), and several other international agencies. Among the planned missions are the three tier-2 Decadal Survey missions from NASA, namely (1) AerosolClouds-Ecosystems (ACE), (2) Geostationary Coastal and Air Pollution Events (GEO-CAPE) [1], and (3) Hyperspectral Infrared Imager (HyspIRI), each with ocean color capability and a unique set of science goals [2]. Under the auspices of the climate initiative, NASA is also planning for an ocean ecosystem sensor as part of the Pre-ACE (PACE) mission planned for a 2019 launch to ensure global ocean color climate data continuity [3].

Mission planning calls for careful consideration of the measurement and instrument requirements in order to achieve the mission goals. One of the challenges in the planning phase is to specify the signal-to-noise ratio (SNR, or sensor sensitivity) for every spectral band at a typical input signal (radiance) received by a satellite sensor.

SNR is a critical parameter to determine the precision of the derived ocean color data products [4], for example, the surface chlorophyll-a concentration (Chl in $\mathrm{mg} \mathrm{m}^{-3}$ ). As an example, Fig. 1(a) shows

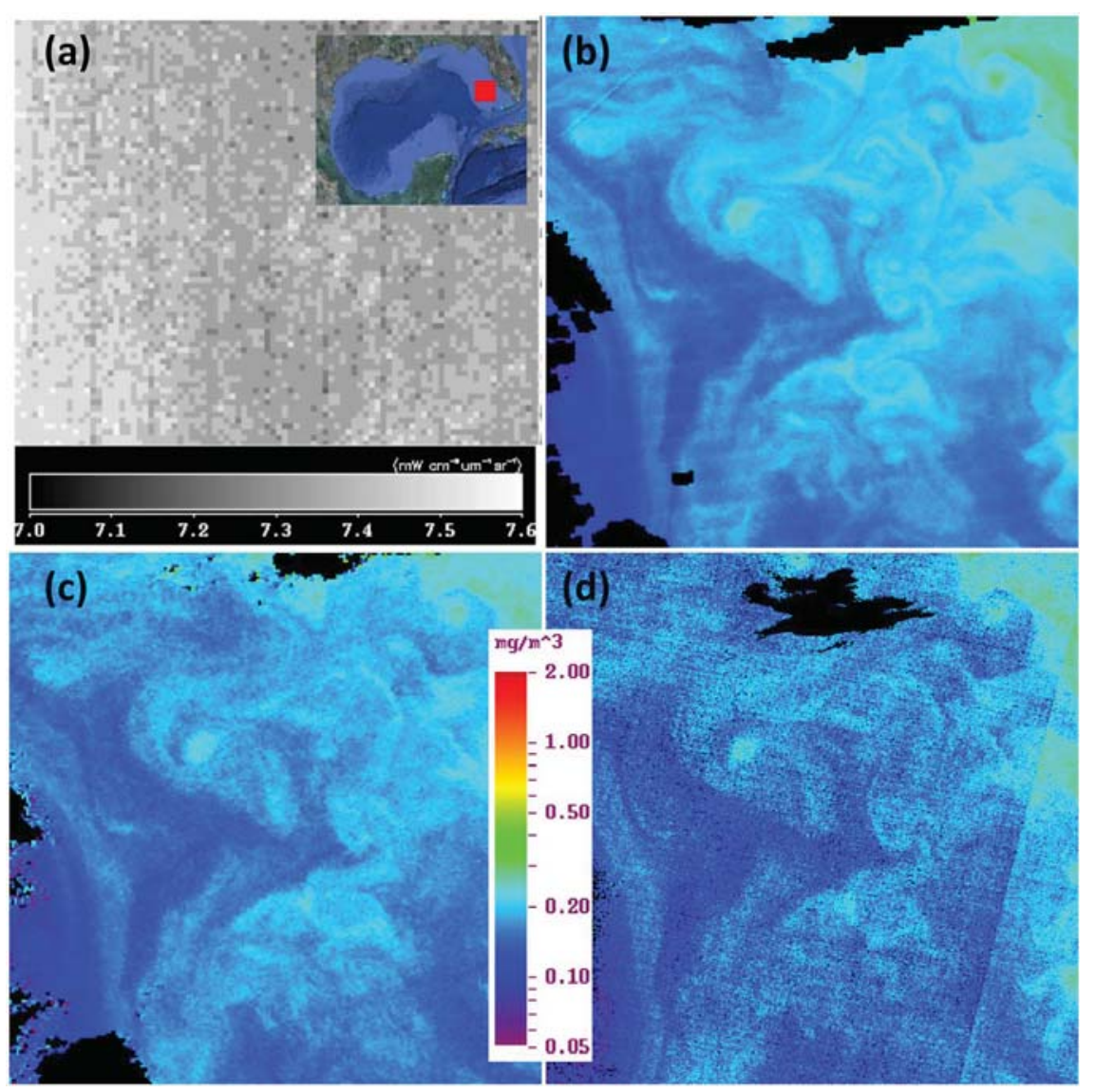

Fig. 1. (Color online) Instrument sensitivity to resolve small changes in at-sensor radiance [(a), $\left.\mathrm{mW} \mathrm{cm}^{-2} \mu \mathrm{m}^{-1} \mathrm{sr}^{-1}\right]$ and surface ocean chlorophyll-a concentrations [(b)-(d), $\mathrm{mg} \mathrm{m}^{-3}$ ] derived from several ocean color instruments. (a) CZCS at-sensor radiance at $443 \mathrm{~nm}$ from a small region $\left(25^{\circ}\right.$ to $27^{\circ} \mathrm{N} ; 85^{\circ} \mathrm{W}$ to $83^{\circ} \mathrm{W}$ ) in the eastern Gulf of Mexico (inset figure), (b)-(d) chlorophyll-a concentrations derived from the same region from MODISA, SeaWiFS, and MERIS-FR on 12 March 2009, respectively, using the same algorithms and software (SeaWiFS Data Analysis System or SeaDAS, version 6.3). The NE-SW linear line on the georeferenced MERIS image is a result of push broom striping noise. Note that MERIS-RR data have much higher SNRs than MERIS-FR data and therefore would not lead to the image noise shown in (d). 
the at-sensor total radiance measured by CZCS in a $2^{\circ} \times 2^{\circ}$ region in the eastern Gulf of Mexico, where the pixelization noise (i.e., variations from pixel to pixel) due to quantization for this 8 bit sensor is apparent. The derived $\mathrm{Chl}$ images from the same box on 12 March 2009 from three ocean color sensors revealed various noise levels [Figs. 1(b)-1(d)], with MODISA showing the lowest noise and MERIS-FR (full resolution) showing the highest noise [note that MERIS-RR (reduced resolution) data have much higher SNRs than MERIS-FR data and therefore would not lead to the image noise shown here; see Section 4]. Using a simple method (see Section 5), the RMS noises from adjacent pixels for various Chl values were quantified and listed in Table 1 . For low-Chl waters $\left(0.01\right.$ to $\left.0.2 \mathrm{mg} \mathrm{m}^{-3}\right)$ the relative pixelization noise decreased with increasing concentration. Such noises would impact the sensitivity to resolve small Chl changes. For example, around $0.1 \mathrm{mg} \mathrm{m}^{-3}$, MERIS-FR cannot resolve a $19.4 \%$ relative change in Chl (corresponding to $0.019 \mathrm{mg} \mathrm{m}^{-3}$ ), while MODISA may resolve changes of $>4.8 \%$ $\left(0.0048 \mathrm{mg} \mathrm{m}^{-3}\right)$. Clearly, different SNRs from various ocean color sensors would lead to varying abilities to resolve small changes in Chl.

In practice, it is always desirable to have high SNR or sensitivity to resolve small changes in the ocean. This is particularly important for the open ocean and colored dissolved organic matter (CDOM)-rich coastal ocean where the water-leaving radiance is very small and the at-sensor signal is dominated by the atmosphere in all spectral bands. However, there is always a trade for high SNR. Due to engineering limitations, the dynamic range of a sensor is often fixed, leading to lower saturation radiance for highsensitivity sensors. Figure 2 shows an example of the price of high sensitivity. While the red-green-blue (RGB) composite image of MODISA, derived from the low-sensitivity land bands, shows a nearly cloud-free image, a big portion of the ocean area is masked (black) in the fluorescence line height (FLH) [5] image derived from several ocean bands. The high-FLH pixels (dark green and yellow colors) were confirmed to contain a $\mathrm{HAB}$, yet due to the saturation of several ocean bands, it is unknown whether the $\mathrm{HAB}$ extended into the masked area. Examination of the radiance data indicated that the maximum valid at-sensor radiance of MODISA is comparable to the
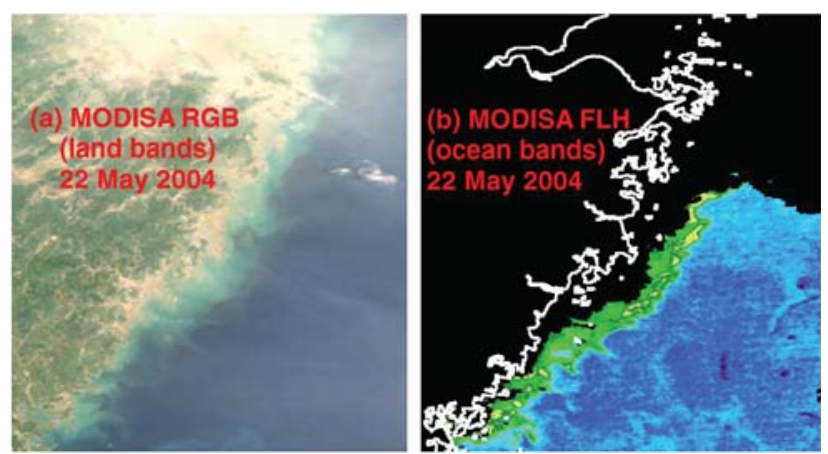

Fig. 2. (Color online) (a) MODISA RGB composite image over coastal waters off Zhejiang Province of China $\left(25^{\circ} 20^{\prime} \mathrm{N}\right.$ to $30^{\circ}$ $40^{\prime} \mathrm{N}$; $119^{\circ} 20^{\prime} \mathrm{E}$ to $124^{\circ} \mathrm{E}$ ); (b) the corresponding fluorescence line height (FLH) image shows an HAB (dark green and yellow colors). Note that although the RGB image derived from the land bands shows minimal cloud cover, a big portion of the ocean area shows no FLH data due to saturation of the corresponding ocean bands. White lines delineate coastlines.

"knee" radiance of SeaWiFS in the green-red bands, but lower than SeaWiFS "knee" radiance in the nearIR bands (Table 2). SeaWiFS has four detectors for each spectral channel; three are set to high gain for ocean imaging and one to low gain for land imaging. The "knee" occurs in the combined signal when the three high-gain detectors are saturated. Thus, thick aerosols, fog, moderate sun glint, or high water turbidity can cause saturation of these MODISA ocean bands, leading to no data in some important regions. This problem is more profound for the Japanese Global Imager (GLI [6]; also see Nakajima et al. [7]), as the $490 \mathrm{~nm}$ saturation radiance is only $6 . \overline{4} \mathrm{~mW} \mathrm{~cm}{ }^{-2} \mu \mathrm{m}^{-1} \mathrm{sr}^{-1}$, much lower than the corresponding SeaWiFS knee radiance (8.53 $\mathrm{mW} \mathrm{cm}^{-2} \mu \mathrm{m}^{-1} \mathrm{sr}^{-1}$, Table 2).

Thus, it is critical to design a sensor with sufficient SNR to resolve small changes in the surface ocean while not saturating the sensor under cloud-free conditions. To correct bright-target adjacency effects from clouds and land (i.e., the at-sensor radiance from the ocean is contaminated by the nearby bright target), it is also desirable to measure the brighttarget (clouds) radiance for most, if not all, clouds. To do this we must first specify the spectral atsensor radiance from typical cloud-free ocean scenes $\left(L_{\text {typical }}\right)$ and maximal spectral radiance from clouds $\left(L_{\max }\right)$. To cover the full range of possible conditions

Table 1. Pixelization Noise in Chl Data Products from Three Ocean Color Instruments ${ }^{a}$

\begin{tabular}{|c|c|c|c|c|c|c|c|}
\hline $\mathrm{Chl}\left(\mathrm{mg} \mathrm{m}^{-3}\right)$ & 0.01 & 0.02 & 0.03 & 0.05 & 0.1 & 0.2 & 0.4 \\
\hline MODISA & $16.5 \%$ & $11.3 \%$ & $9.3 \%$ & $7.5 \%$ & $4.8 \%$ & $2.8 \%$ & $2.8 \%$ \\
\hline SeaWiFS & $21.9 \%$ & $16.7 \%$ & $15.8 \%$ & $14.5 \%$ & $8.5 \%$ & $6.1 \%$ & $7.1 \%$ \\
\hline MERIS-FR & $74.2 \%$ & $51.5 \%$ & $40.1 \%$ & $29.5 \%$ & $19.4 \%$ & $12.1 \%$ & $8.2 \%$ \\
\hline MERIS-RR & $21.6 \%$ & $18.4 \%$ & $16.4 \%$ & $12.9 \%$ & $8.1 \%$ & $4.3 \%$ & $4.4 \%$ \\
\hline
\end{tabular}

${ }^{a}$ The statistics were derived from at least $>10,000$ pixels for each concentration. Chl data were derived from sensor measurements using near identical algorithms and processing steps defined in SeaDAS6.3. Note that MERIS data used here are both full resolution (FR, 300 m) and reduced resolution (RR, $1.2 \mathrm{~km}$ ) as compared with $1.1 \mathrm{~km}$ of MODISA and SeaWiFS (both used Local Area Coverage, or LAC, data). MERIS data processed using similar algorithms but different software, such as those from the European Space Agency, showed slightly different RMS noise than that listed in the table. 
Table 2. Maximum Valid Radiance of MODISA and Knee Radiance of SeaWiFS for All Ocean Bands, Determined from Measurements in 2004

\begin{tabular}{lccccccccc}
\hline$\lambda(\mathrm{nm})$ & $412(412)^{b}$ & $443(443)$ & $488(490)$ & $531(510)$ & $547(555)$ & $667(670)$ & 678 & $748(765)$ & $869(865)$ \\
\hline MODISA max valid & 19.99 & 15.90 & 11.56 & 9.13 & 6.97 & 3.50 & 3.31 & 2.24 & 1.31 \\
MODISA saturation $^{c}$ & 26.9 & 19.0 & 14.0 & 11.1 & 8.8 & 4.2 & 4.2 & 3.5 & 2.5 \\
SeaWiFS knee & 11.76 & 10.87 & 8.53 & 7.29 & 5.97 & 3.37 & N/A & 2.46 & 2.09 \\
\hline
\end{tabular}

${ }^{a}$ Radiances are in units of $\mathrm{mW} \mathrm{cm}{ }^{-2} \mu \mathrm{m}^{-1} \mathrm{sr}^{-1}$. MODISA maximum valid radiance is the radiance above which the linear relationship between the sensor-recorded digital number and calibrated radiance no longer holds. As a reference, MODIS saturation radiance refers to the radiance preceding sensor saturation [11]. SeaWiFS Knee radiance was derived using a second derivative analysis from the digital number $(\mathrm{DN})$ versus radiance relationship.

${ }^{b}$ Wavelength (nm) in parenthesis is for SeaWiFS.

${ }^{c}$ Data provided by Franz et al. [11].

from a geostationary platform from early morning to late afternoon, these two quantities, together with the SNR under typical conditions, need to be defined at various solar zenith angles (SZAs) in order to help with sensor design and mission planning (e.g., determine integration time).

Unfortunately, published values for SNR, $L_{\text {typical }}$, and $L_{\max }$ in either refereed or gray literature were not defined in a consistent way for previous and existing ocean color sensors, making it difficult to learn from the past. Some instruments specified noiseequivalent radiances (NE $\Delta L)$ instead of SNRs [8], and some defined SNRs from laboratory measurements using input radiance that is not typical for the ocean (e.g., MODIS [9]). Even when the solar diffusers on SeaWiFS and MODIS were used to "measure" the SNRs on orbit, the input radiances were different $[\underline{9}, 10]$, and adjustment of the input radiance to realistic typical radiance over the ocean is necessary to determine the SNRs [11]. To date, for past and existing ocean color sensors there is a lack of consistent SNR assessment under the same radiance input for typical measurement conditions over the ocean. Such information can serve as an important reference to help design future ocean color missions such as GEO-CAPE and PACE.

Thus, given the need for these parameters under uniform measurement conditions, this study was designed to

(1) determine spectral $L_{\text {typical }}$ and $L_{\max }$ from MODISA measurements under various SZAs,

(2) assess SNRs of commonly used ocean color sensors under the same $L_{\text {typical }}$, and

(3) provide tabulated references and recommendations for future ocean color missions.

\section{Data Sources}

$L_{\text {typical }}$ and $L_{\max }$ were determined from MODISA measurements. MODISA data were obtained from the NASA Goddard Space Flight Center (GSFC). To assure sufficient coverage under all possible conditions, MODIS data covering all of North America and adjacent oceans $\left(0^{\circ}-70^{\circ} \mathrm{N}\right.$ and $\left.135^{\circ}-45^{\circ} \mathrm{W}\right)$ during different months of 2004 were selected. A total of 255 Level-0 data granules were processed using the software package SeaDAS (version 6.3) to derive the at-sensor radiance (Level-1B), SZAs, surface Chl, and quality flags for each pixel (Level-2).
SNRs were estimated from MODISA and several other past and current ocean color sensors, including SeaWiFS, MERIS-FR, MERIS-RR, CZCS, OCM, and GOCI. Level-1 at-sensor radiance data covering the same North America ocean areas were obtained from various sources, including NASA GSFC (for SeaWiFS LAC data, MERIS-FR, CZCS), the European Space Agency (MERIS-RR), the Earth Scan Lab of Louisiana State University (for OCM-1), and Korea Ocean Satellite Center (for GOCI) (Table 3). These data were processed in the same manner as with MODISA to generate at-sensor radiance, surface Chl, and quality flags for each pixel (Level-2).

Although high spatial resolution sensors (e.g., Landsat TM and ETM+, HJ-CCD, EO-1 Hyperion) were designed primarily for land use, there have been demonstrations that they could also be used to study coastal blooms and water quality [12-15]. More recently, the Hyperspectral Imager for the Coastal Ocean (HICO) was installed on the Japanese Experiment Module Exposed Facility (JEM-EF) on the International Space Station and has been collecting data for selected sites in the global coastal zones since September 2009 [16]. In addition, the geostationary GOES Imager is equipped with a wide band (550-750 nm centered at $650 \mathrm{~nm}$, GOES I-M Data Book) that could also be used for coastal ocean studies. At-sensor radiance data from these measurements have also been obtained to estimate their SNRs over the ocean under the same typical conditions. Specifically, Landsat TM and ETM+ and EO-1 Hyperion data were obtained from the U.S. Geological Survey [17]. HJ-CCD data were obtained from the China Centre for Resources Satellite Data and Application (http://www.cresda.com/n16/index .html). HICO data were obtained from the data archive at Oregon State University [18]. GOES Imager data were obtained from the National Oceanic and Atmospheric Administraion (NOAA) Comprehensive Large Array-data Stewardship System (CLASS). The characteristics of these are all listed in Table $\underline{3}$ (see informations sources in [19]).

\section{3. $L_{\text {typical }}$ and $L_{\max }$ Determined from MODISA Measurements}

For each MODIS granule and spectral band, $L_{\text {typical }}$ was derived from the Level-1 at-sensor radiance from cloud-free ocean pixels. These pixels were defined by 


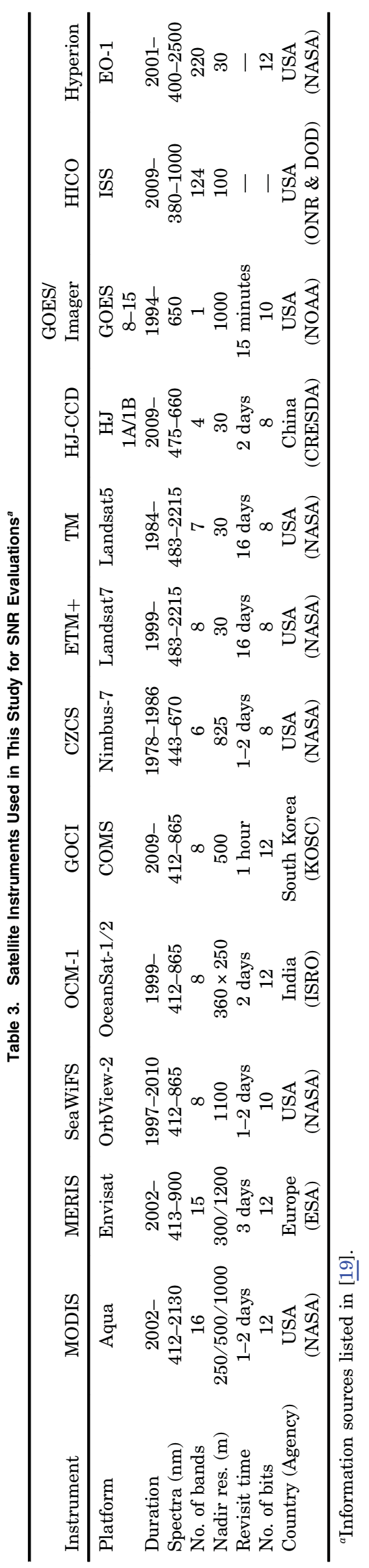




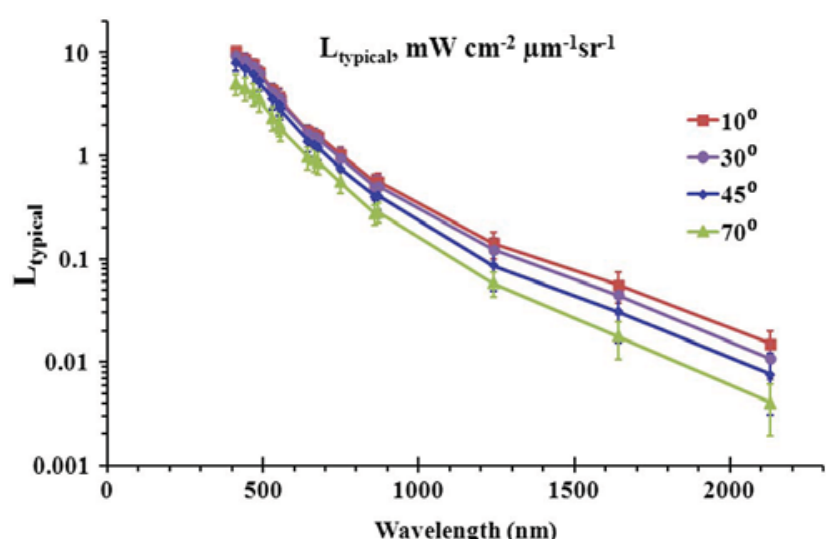

Fig. 3. (Color online) $L_{\text {typical }}$ of MODISA determined from the 255 MODIS scenes using clear water pixels under a clear sky at various SZAs. The data are tabulated in Table 4 .

the quality control flags in the corresponding Level-2 data. The pixels were grouped by various SZAs $\left(10^{\circ} \pm 1^{\circ}, 30^{\circ} \pm 1^{\circ}, 45^{\circ} \pm 1^{\circ}\right.$, and $\left.70^{\circ} \pm 1^{\circ}\right)$ in order to determine $L_{\text {typical }}$ as a function of SZA. For each group, the mean radiance from all qualified pixels was regarded as $L_{\text {typical }}$ for that particular granule. Then, $L_{\text {typical }}$ for the predefined SZA was computed as the mean and standard deviation radiances of all individual $L_{\text {typical }}$ values from the 255 granules. The results are shown in Fig. $\underline{3}$ and listed in Table $\underline{4}$. Clearly, $L_{\text {typical }}$ decreases with increasing SZA. In reality, the at-sensor radiance is a function of not only SZA but also sensor angle as well as the variable aerosols and ocean properties. However, because our purpose was to determine the at-sensor radiance under typical measurement conditions rather than under exact atmospheric and oceanic conditions, these tabulated values (mean and standard deviations) should be able to serve as references for future sensors and to estimate SNRs (see Subsection 4.A). Indeed, for all ocean bands in the visible, $L_{\text {typical }}$ at $\mathrm{SZA}=45^{\circ}$ is significantly higher than those listed by NASA prelaunch sensor specifications for MODIS (Table 4). In contrast, the two near-infrared (NIR) ocean bands (748 and $869 \mathrm{~nm}$ ) and all land bands (except 469 and $555 \mathrm{~nm}$ ) showed significantly lower $L_{\text {typical }}$ than the NASA prelaunch specifications, which were based on typical land reflectances. Because $L_{\text {typical }}$ at SZA $=45^{\circ}$ was used in this study to determine the SNRs, such derived SNRs could not be compared directly with those listed in the NASA specifications.

$L_{\max }$ was derived from cloud pixels. Because all MODISA ocean bands (8-16) saturated over clouds, only land bands (1-7) were used. For each MODISA granule, the following steps were used to determine $L_{\max }$.

(1) Cloud pixels were selected using quality control flags in the MODISA Level-2 data.

(2) Of these cloud pixels, for each band, the top 5\% and $1 \%$ brightest pixels were selected, respectively. The extreme outliers due to detector malfunctioning were discarded in this step.

(3) The mean radiance of these qualified pixels was regarded as $L_{\max }$ for the selected granule.

Similar to the calculation of $L_{\text {typical }}, L_{\max }$ was computed as the mean and standard deviation of all individual $L_{\max }$ values from the 255 granules. These steps were repeated for each predefined SZA $\left(10^{\circ}\right.$, $30^{\circ}, 45^{\circ}$ and $70^{\circ}$ ). Results for the top 5\% and $1 \%$

Table 4. $L_{\text {typical }}\left(\right.$ Units: $\left.\mathrm{mW} \mathrm{cm} \mathrm{cm}^{-2} \mu \mathrm{m}^{-1} \mathrm{sr}^{-1}\right)$ of MODISA over the Ocean $\left(0^{\circ}-70^{\circ} \mathrm{N}\right.$ and $\left.135^{\circ}-45^{\circ} \mathrm{W}\right)$ Determined from On-Orbit Measurements during All Months of $2004^{a}$

\begin{tabular}{|c|c|c|c|c|c|c|c|c|c|c|}
\hline \multirow[b]{2}{*}{ Band \# } & \multirow[b]{2}{*}{$\lambda(\mathrm{nm})$} & \multicolumn{2}{|c|}{$\mathrm{SZA}=10^{\circ}$} & \multicolumn{2}{|c|}{$\mathrm{SZA}=30^{\circ}$} & \multicolumn{2}{|c|}{$\mathrm{SZA}=45^{\circ}$} & \multicolumn{2}{|c|}{$\mathrm{SZA}=70^{\circ}$} & \multirow[b]{2}{*}{ NASA Spec } \\
\hline & & Mean & STD & Mean & STD & Mean & STD & Mean & STD & \\
\hline 8 & 412 & 10.27 & 0.42 & 9.47 & 1.50 & 8.07 & 1.46 & 4.95 & 1.17 & 4.49 \\
\hline 9 & 443 & 8.75 & 0.42 & 8.38 & 1.38 & 6.98 & 1.33 & 4.50 & 1.10 & 4.19 \\
\hline $3^{c}$ & $469^{c}$ & 7.80 & 0.46 & 7.43 & 1.26 & 6.19 & 1.19 & 4.01 & 1.02 & 3.63 \\
\hline 10 & 488 & 6.52 & 0.61 & 6.28 & 1.10 & 5.23 & 1.01 & 3.49 & 0.87 & 3.21 \\
\hline 11 & 531 & 4.36 & 0.55 & 4.17 & 0.77 & 3.55 & 0.73 & 2.33 & 0.59 & 2.79 \\
\hline 12 & 547 & 3.74 & 0.69 & 3.67 & 0.71 & 3.13 & 0.66 & 2.05 & 0.52 & 2.10 \\
\hline $4^{c}$ & $555^{c}$ & 3.45 & 0.42 & 3.35 & 0.62 & 2.85 & 0.61 & 1.85 & 0.47 & 2.90 \\
\hline $1^{c}$ & $645^{*}$ & 1.72 & 0.21 & 1.65 & 0.33 & 1.39 & 0.32 & 0.96 & 0.23 & 2.18 \\
\hline 13 & 667 & 1.61 & 0.21 & 1.53 & 0.32 & 1.27 & 0.30 & 0.92 & 0.22 & 0.95 \\
\hline 14 & 678 & 1.53 & 0.20 & 1.43 & 0.30 & 1.19 & 0.29 & 0.87 & 0.21 & 0.87 \\
\hline 15 & 748 & 1.04 & 0.16 & 0.95 & 0.22 & 0.75 & 0.20 & 0.56 & 0.13 & 1.02 \\
\hline $2^{c}$ & $859^{c}$ & 0.55 & 0.11 & 0.50 & 0.12 & 0.40 & 0.11 & 0.27 & 0.059 & 2.47 \\
\hline 16 & 869 & 0.56 & 0.11 & 0.51 & 0.13 & 0.41 & 0.12 & 0.29 & 0.060 & 0.62 \\
\hline $5^{c}$ & $1240^{c}$ & 0.14 & 0.042 & 0.12 & 0.038 & 0.086 & 0.038 & 0.058 & 0.016 & 0.54 \\
\hline $6^{c}$ & $1640^{c}$ & 0.056 & 0.019 & 0.045 & 0.016 & 0.031 & 0.016 & 0.018 & 0.007 & 0.73 \\
\hline $7^{c}$ & $2130^{c}$ & 0.015 & 0.005 & 0.011 & 0.004 & 0.008 & 0.005 & 0.004 & 0.002 & 0.10 \\
\hline
\end{tabular}

${ }^{a}$ The last column lists NASA specifications [9]. The mean and STD values for SZA $=45^{\circ}$ in columns seven and eight were used as the typical radiance to determine sensor SNR (i.e., sensitivity) for 10 heritage instruments.

${ }^{b}$ The NASA prelaunch MODIS specifications were provided by Xiong et al. [9]. For SeaWiFS, the input radiances for SNR specifications were $[9.10,8.41,6.56,5.64,4.57,2.46,1.61,1.09]$ for the eight spectral bands at [412, 443, 490, 510, 555, 670, 765, 865 nm] (see [10,45]).

'These bands were designed for land and atmospheric applications, but they could also be used to study the ocean. 

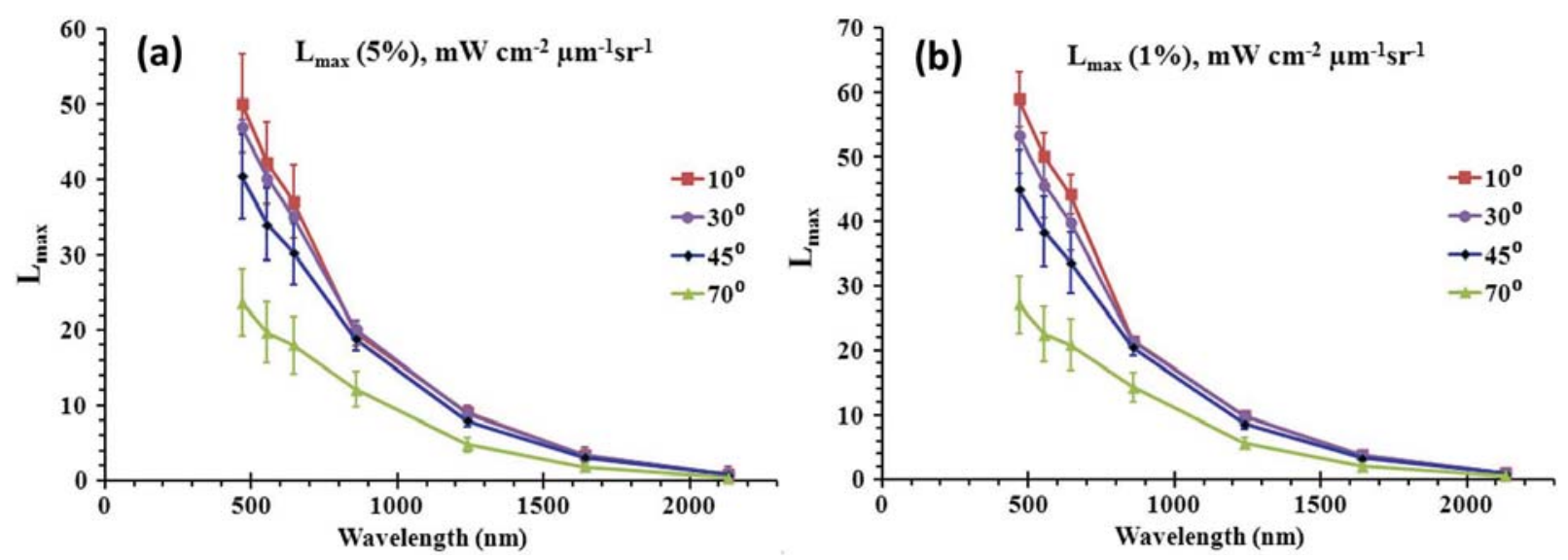

Fig. 4. (Color online) $L_{\max }$ of MODISA determined from the 255 MODIS scenes using cloud pixels at various SZAs. (a) $L_{\text {max }}$ from the top $5 \%$ of the brightest pixels; (b) $L_{\max }$ from the top $1 \%$ of the brightest pixels. The data are tabulated in Tables $\underline{5}$ and $\underline{6}$, respectively.

brightest pixels are shown in Figs. 4(a) and 4(b), respectively, with the $L_{\max }$ values listed in Tables $\underline{5}$ and 6 , respectively. Compared with their corresponding $\bar{L}_{\text {typical }}$ values, $L_{\max }$ values were much higher. Further, there was some variability between $L_{\max }$ from different images, resulting in about $10 \%$ standard deviation. For each band, $L_{\max }$ decreased with increasing SZA. This result, together with similar characteristics in $L_{\text {typical }}$ (decreased with increasing SZA), may be used to help design future satellite missions on geostationary platforms. Note that if a sensor has $L_{\max }$ values as listed in Table 5 , measurements over turbid atmosphere or moderate sun glint such as in Fig. $\underline{2}$ will not be saturated.

\section{SNR at $L_{\text {typical }}$}

\section{A. Methods}

For a radiometer, the SNR is defined as the ratio of the signal electrons to the number of unwanted or noise electrons on the detector:

$$
\begin{aligned}
\operatorname{SNR}(\text { Signal } / \text { Noise }) & =n_{\text {signal }} / n_{\text {noise }}, \\
n_{\text {signal }} & =(\Phi / h \nu) * t * A * \eta,
\end{aligned}
$$

where $\Phi$ is the power density $\left(\mathrm{W} \mathrm{m}^{-2}\right)$ falling on the detector, $h \nu$ is the photon energy (W $\mathrm{s}$ ), $t$ is the exposure time $(\mathrm{s}), \mathrm{A}$ is the pixel area $\left(\mathrm{m}^{2}\right)$, and $\eta$ is the quantum efficiency of the detector at that wavelength.

Three noise signals are typically identified: $n_{\text {photon }}$ or shot noise, $n_{\text {det }}$ or detector noise, and $n_{\text {readout }}$ or the noise associated with the readout electronics. These noise sources are not correlated, so the total noise is

$$
n_{\text {noise }}=\operatorname{sqrt}\left(n_{\text {photon }}^{2}+n_{\text {det }}^{2}+n_{\text {readout }}^{2}\right)
$$

For modern detectors and electronics, $n_{\text {photon }}$ dominates the noise with $n_{\text {photon }}^{2} \gg n_{\text {det }}^{2}+n_{\text {readout }}^{2}$, because the input signal even from a dark ocean surface still overwhelms the total noise [20,21]. For the purposes of this study, we assume that $n_{\text {noise }}$ can be approxi-

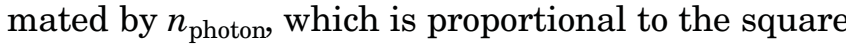
root of the signal. SNR is thus a function of the detected signal. To properly define SNR for an ocean color sensor, we need to use a typical ocean spectral signal for this calculation. For this practical consideration, we define signal as the radiance $\left(\mathrm{m} \mathrm{W} \mathrm{cm}{ }^{-2} \mu \mathrm{m}^{-1} \mathrm{sr}^{-1}\right.$ ) measured from the target, and noise is the associated random variability [22]. This is different from some of the definitions in engineering or instrument design, where $n_{\text {photon }}$ collected from a finite field of view or falling on a detector is considered as the signal. In practice, all measured signals are digitized, so digitization round-off represents another noise source that can cause errors in

\begin{tabular}{|c|c|c|c|c|c|c|c|c|}
\hline \multirow[b]{2}{*}{ Wavelength (nm) } & \multicolumn{2}{|c|}{$\mathrm{SZA}=10^{\circ}$} & \multicolumn{2}{|c|}{$\mathrm{SZA}=30^{\circ}$} & \multicolumn{2}{|c|}{$\mathrm{SZA}=45^{\circ}$} & \multicolumn{2}{|c|}{$\mathrm{SZA}=70^{\circ}$} \\
\hline & Mean & STD & Mean & STD & Mean & STD & Mean & STD \\
\hline 469 & 50.15 & 6.55 & 46.99 & 6.11 & 40.45 & 5.61 & 23.68 & 4.43 \\
\hline 555 & 42.21 & 5.50 & 40.20 & 5.18 & 34.06 & 4.86 & 19.64 & 4.07 \\
\hline 645 & 37.09 & 4.80 & 35.09 & 4.48 & 30.27 & 4.20 & 18.02 & 3.76 \\
\hline 859 & 19.68 & 1.69 & 20.18 & 1.28 & 18.89 & 1.63 & 12.13 & 2.36 \\
\hline 1240 & 9.08 & 0.68 & 8.97 & 0.74 & 7.95 & 0.82 & 4.78 & 0.97 \\
\hline 1640 & 3.40 & 0.38 & 3.36 & 0.37 & 3.06 & 0.35 & 1.78 & 0.38 \\
\hline 2130 & 0.80 & 0.09 & 0.78 & 0.13 & 0.73 & 0.11 & 0.44 & 0.09 \\
\hline
\end{tabular}
the derived data products [4]. In SNR evaluations,

Table 5. $L_{\max }$ of MODISA Land Bands over Clouds (5\% Brightest Pixels) (Units: $\left.\mathrm{mW} \mathrm{cm}^{-2} \mu \mathrm{m}^{-1} \mathrm{sr}^{-1}\right)^{a}$

${ }^{a}$ Note that MODISA ocean bands all saturate over bright clouds. 
Table 6. Same as Table $\underline{5}$, but $L_{\max }$ was Derived from the $1 \%$ Brightest Pixels (Units: $\mathrm{mW} \mathrm{cm}^{-2} \mu \mathrm{m}^{-1} \mathrm{sr}^{-1}$ )

\begin{tabular}{|c|c|c|c|c|c|c|c|c|}
\hline \multirow[b]{2}{*}{ Wavelength (nm) } & \multicolumn{2}{|c|}{$\mathrm{SZA}=10^{\circ}$} & \multicolumn{2}{|c|}{$\mathrm{SZA}=30^{\circ}$} & \multicolumn{2}{|c|}{$\mathrm{SZA}=45^{\circ}$} & \multicolumn{2}{|c|}{$\mathrm{SZA}=70^{\circ}$} \\
\hline & Mean & STD & Mean & STD & Mean & STD & Mean & STD \\
\hline 469 & 58.92 & 4.28 & 53.35 & 6.00 & 44.91 & 6.13 & 27.15 & 4.45 \\
\hline 555 & 50.05 & 3.57 & 45.59 & 4.99 & 38.42 & 5.40 & 22.49 & 4.30 \\
\hline 645 & 44.21 & 3.00 & 39.88 & 4.36 & 33.61 & 4.67 & 20.88 & 3.94 \\
\hline 859 & 21.50 & 0.35 & 21.43 & 0.47 & 20.48 & 1.21 & 14.27 & 2.36 \\
\hline 1240 & 9.90 & 0.41 & 9.83 & 0.63 & 8.67 & 0.87 & 5.61 & 0.90 \\
\hline 1640 & 3.78 & 0.24 & 3.76 & 0.33 & 3.35 & 0.37 & 1.97 & 0.32 \\
\hline 2130 & 0.93 & 0.07 & 0.93 & 0.13 & 0.81 & 0.11 & 0.54 & 0.09 \\
\hline
\end{tabular}

${ }^{a}$ Note that for $\mathrm{SZA}=10^{\circ}$, the listed $L_{\max }$ values correspond to reflectances of $91 \%, 87 \%, 89 \%, 71 \%, 69 \%$, 50, and $30 \%$, respectively.

this round-off-induced noise is considered together with inherent sensor noise without distinguishing the sources. Obviously, two quantities need to be determined to calculate SNR: input signal (i.e., radiance) and measured noise.

For a given sensor, input signal affects SNR. Thus, to compare SNRs between different sensors, the input signal needs to be kept the same. This has been problematic in the past, because most published SNRs were referenced against different input signals in laboratory measurements, and Xiong et al. [9] and Eplee et al. [10] used onboard solar diffusers to estimate SNRs for SeaWiFS and MODIS on orbit, respectively, at predefined input signals. However, these predefined signals were different, making a direct SNR comparison between SeaWiFS and MODIS difficult. In addition, many other ocean color instruments are not equipped with an onboard solar diffuser, suggesting that an alternative method is required to define the input signal. Indeed, for remotely sensed imagery, the signal can be considered as the mean of the calibrated radiance (or gray-level count) from a spatially homogenous target $[20,23]$. This approach was adapted in the current study to restrict the SNR calculations to those measurements where the at-sensor radiance was equal to MODISA $L_{\text {typical }}$ at $\mathrm{SZA}=45^{\circ}$ (Table $\underline{4}$, shaded columns). For sensors with different spectral bands, the tabulated $L_{\text {typical }}$ values were interpolated.

Similar to the restrictions on the input signal, noise can be represented by the standard deviation over a spatially homogeneous target $[24,25]$. The potential problem of this approach, however, is that the standard deviation of the selected target may contain real ocean or atmosphere changes within the target in addition to sensor noise. Thus, the target must be selected carefully, for example, from oligotrophic oceans where the horizontal gradient is small. This is not trivial in practice. Wettle et al. [26] demonstrated a method of Automated Local Convergence Locator (ALCL) to find a sampling size of $33 \times 33$ pixels when the standard deviation approached an asymptotic value. Gao [23] proposed that the histogram mode of all standard deviations from predefined small windows could represent the noise. However, it is still unknown whether each target within the small window is homogenous. In this study, the Gao [23] approach was adapted with an added objective analysis of homogeneity of each small window. Briefly, if the maximum/minimum
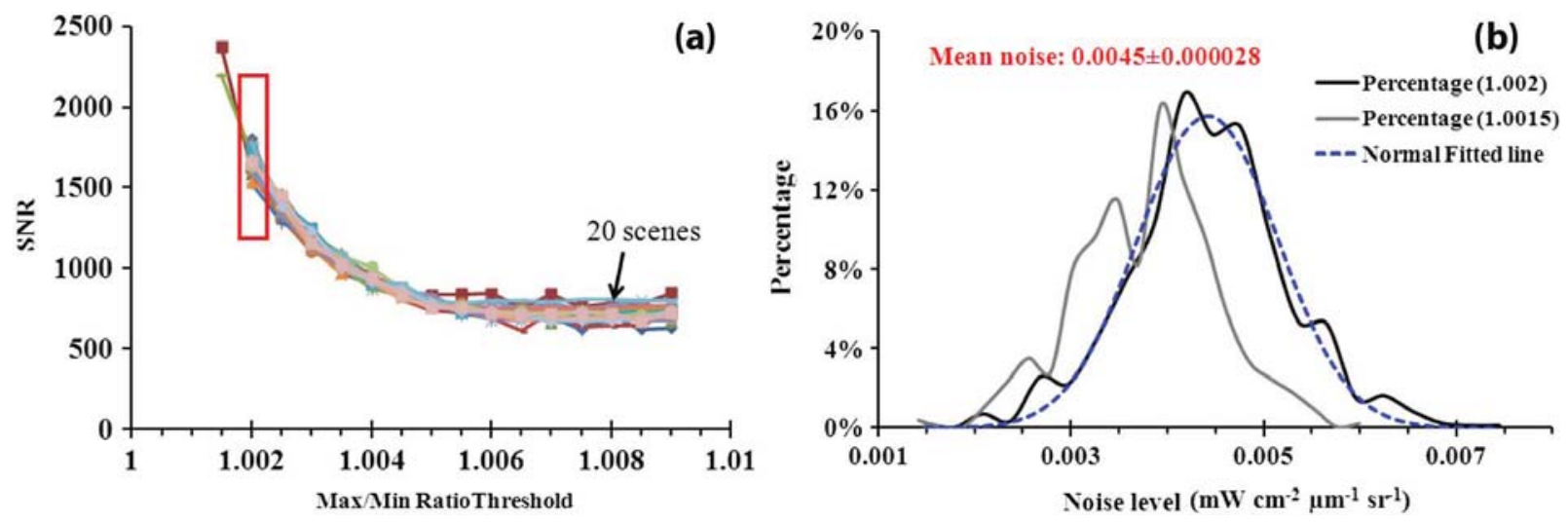

Fig. 5. (Color online) (a) SNR of the MODISA $412 \mathrm{~nm}$ band determined using different thresholds of maximum/minimum ratio within small areas (running windows on an image). The SNR values of individual images become stable (i.e., they are similar from image to image) when the threshold is $\geq 1.002$. Below this threshold, many images did not yield any qualified small windows, and SNRs determined from individual images varied substantially. To minimize the potential impact of inhomogeneous water and/or atmosphere on the SNR determination, the max/min threshold ratio in this study was chosen to be 1.002 . The same method was applied to all other bands to determine the threshold value to assure spatial homogeneity of the target; (b) Noise level distribution of all qualified small windows from a typical image. The distribution is normal (according to the Gaussian fit) when the max/min threshold equals 1.002 , while it is not normal when the threshold equals 1.0015 . 


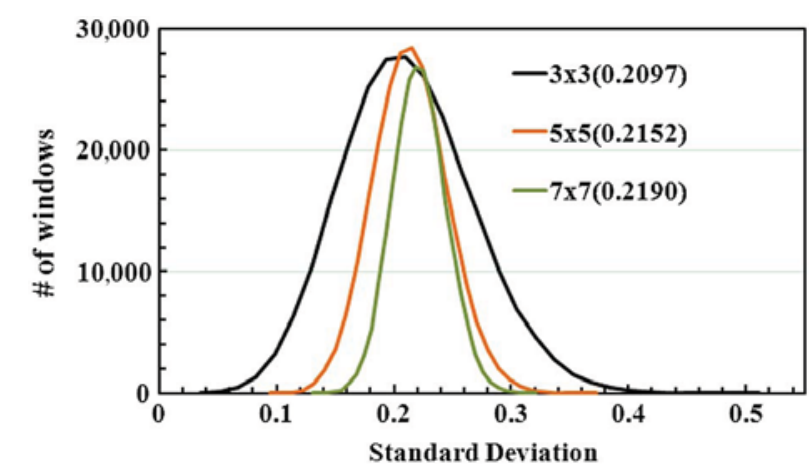

Fig. 6. (Color online) Distribution of noise, defined as the standard deviation of all pixels in a given window (either $3 \times 3,5 \times 5$, or $7 \times 7$ ), as a function of window size from a simulated image. The image was assigned a unit value for all pixels, with added random noise from -1.0 to 1.0 with a Gaussian normal distribution. The different window sizes led to $<5 \%$ changes in their histogram modes (numbers in parenthesis), suggesting that image noise (and thus SNR) is not sensitive to the choice of window size.

radiance ratio within a small window was smaller than a certain threshold, the target in the window could be considered as homogeneous. The threshold was determined through an objective method detailed below.

In summary, for every sensor in the study, the following steps were used to determine the SNR at input signal $=L_{\text {typical }}$ for each spectral band.

(1) In each image, only clear-water pixels were selected to calculate statistics. For MODISA, SeaWiFS, CZCS, MERIS-FR, and MERIS-RR, after discarding all pixels associated with the quality control flags, the pixels with at-sensor radiance $\left(L_{t}\right)$ within $L_{\text {typical }} \pm 1$ standard deviation (STD) and $\mathrm{Chl}<0.07 \mathrm{mg} \mathrm{m}^{-3}$ were selected. A Chl value of $0.07 \mathrm{mg} / \mathrm{m}^{3}$ is the threshold to define the most oligotrophic ocean waters [27]. For all other sensors (OCM, GOCI, TM, ETM+, HJ-CCD, GOES, HICO, Hyperion), clear-water pixels that meet the criteria of $L_{\text {typical }} \pm 1$ STD were selected by visually examining the RGB images (to exclude land and clouds) and the corresponding $\mathrm{Chl}$ images from concurrent measurements by MODISA using the same criteria as with MODISA. Note that the selection of clear-water pixels did not consider the satellite viewing angle even though the pixel resolution degrades from nadir view to side view. This is because that radiance (or number of collected photons) does not change with viewing angle for a fixed instantaneous field-of-view (IFOV) from a given sensor, according to the radiance invariance law for Lambertian surfaces.

(2) The qualified pixels were further screened using the following method. All qualified pixels were divided into $3 \times 3$ small windows. To assure minimal variations within the individual windows so that the variations were due to sensor noise rather than due to real variations in the ocean or in the atmosphere, a threshold of maximum/minimum ratios from all windows was used. The windows whose maximum/ minimum ratios were above this threshold were discarded in the SNR calculations. STD was determined from each window where all $3 \times 3$ pixels had valid observations, and the histogram mode of all standard deviations was regarded as the instrument noise for that particular image. SNR was calculated as $L_{\text {typical }}$ divided by noise. Because the sensor's SNR only depends on the sensor itself and should not change from image to image for the same $L_{\text {typical }}$, by trial and error the threshold was determined when it yielded a relatively stable SNR from all images and when it yielded a normal-distributed histogram of all STDs (i.e., noise). Below this threshold, SNRs could not be determined from some of the individual

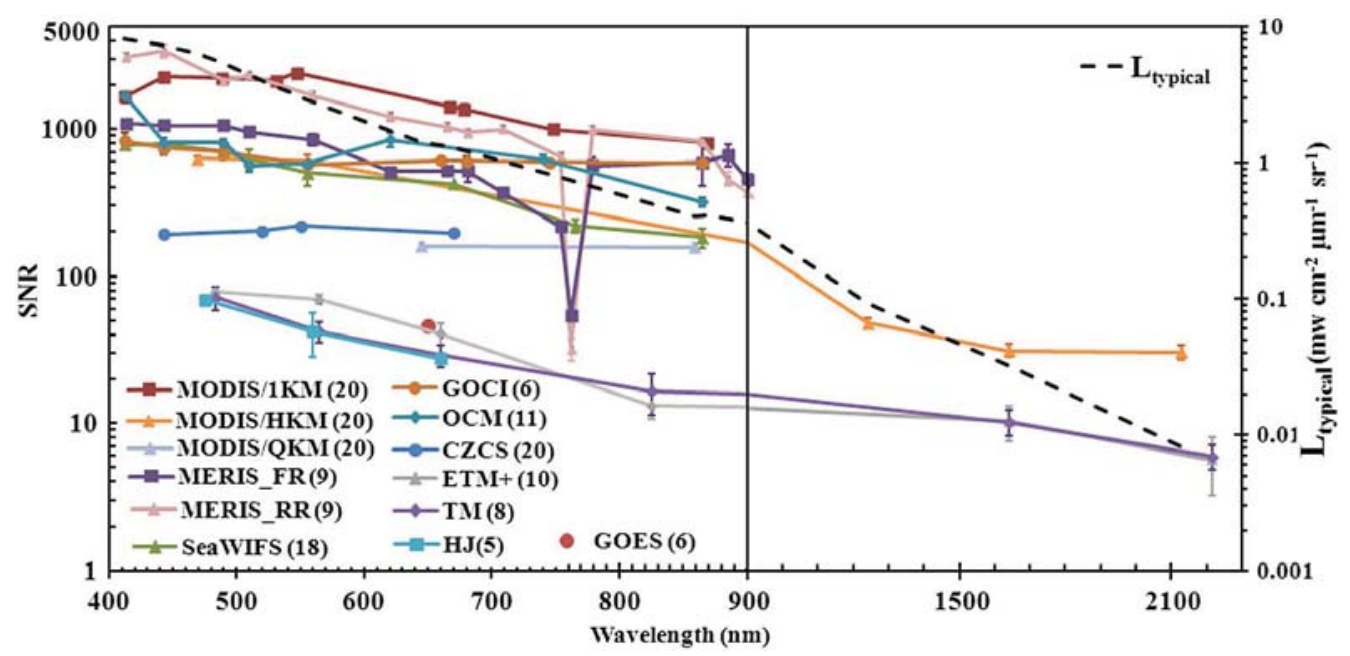

Fig. 7. (Color online) SNRs of all spectral bands from the 10 multiband instruments, determined from their individual measurements at near-identical $L_{\text {typical }}$ (right axis, dashed line). Note that the MODISA bands were divided into three groups: $1 \mathrm{KM}$ (ocean bands between 413 and $869 \mathrm{~nm}$ ); HKM (land bands at 469, 555, 1240, 1640, and $2130 \mathrm{~nm}$ ), and QKM (land bands at 645 and $859 \mathrm{~nm}$ ). MERIS SNRs were determined from both FR and RR data. Because they were determined from multiple images, both mean and standard deviations (vertical bars) were plotted. These data are tabulated in Table $\underline{7}$. The numbers in the parentheses represent the number of images used in determining the SNRs. 


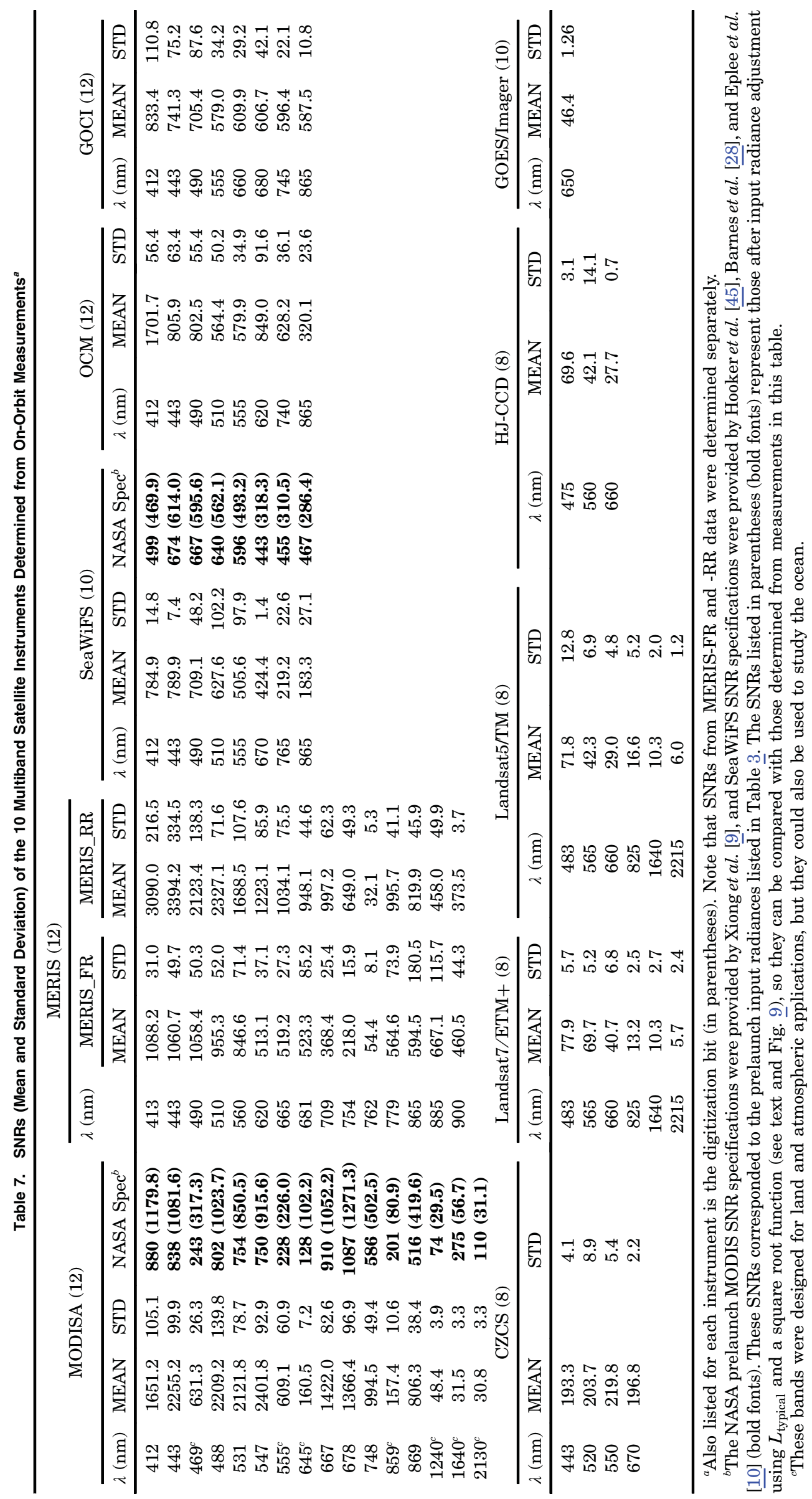


images. A Gaussian fit was used to determine whether the noise had a normal distribution. If the significance level ( $P$ value) of the T-test was $<0.05$, the noise distribution was considered to be normal. Figure 5 shows the concept using the MODISA $412 \mathrm{~nm}$ band as an example. When the threshold was selected as $<1.002$, SNRs from different images varied substantially and many images yielded no qualified small windows to start with. At 1.002, SNRs from all images stabilized, leading to a mean SNR of 1651.2 [Fig. 5(a)] together with a normal distribution in the STD statistics [Fig. 5(b)]. In contrast, a threshold of 1.0015 would lead to a non-normal distribution in the STD statistics. Thus, a max/min threshold of 1.002 was selected to screen all pixels, and the SNR was determined as the mean SNR from all examined images for this band. The procedure was repeated for each band and for each sensor with its max/min threshold ratio derived independently.

(3) The sensitivity of SNR calculations to the varying window size was also studied using simulations. A $500 \times 500$ artificial image with a constant pixel value was assumed, and Gaussian-distributed random noise, with minimum and maximum values of -1 and 1 , respectively, was added to the image. For each window size of $3 \times 3,5 \times 5$, and $7 \times 7$, the noise of each small window was determined as the STD. The histogram of all STDs is shown in Fig. 6, where the histogram mode appears to be insensitive to window size. Because under natural conditions more pixels selected in a small window would result in a higher likelihood of containing natural variability (in either the ocean or the atmosphere, or both), a $3 \times 3$ window should be the best choice and, thus, was chosen to estimate SNRs for all sensors.

\section{B. Results}

Such determined SNRs for all sensors are presented in Fig. 7 and tabulated in Table $\underline{7}$. Of all sensors evaluated, MODISA ocean bands and MERIS-RR data showed the highest SNRs, with MERIS-RR SNRs reaching 3000 for the blue bands. The most striking result was that all MODISA ocean bands showed much higher SNRs than the NASA specifications (bold font in Table 7; see Xiong et al. [9]), especially in the blue-green bands. One reason leading to this discrepancy is that the SNRs in the blue-green were determined from $L_{\text {typical }}$ much higher than the NASA specified input radiances (last column in Table 4 ). However, even after the input radiance from the NASA specifications was adjusted to $L_{\text {typical }}$ (bold font in parentheses in Table 7), MODISA SNRs in the ocean bands were still significantly higher than the specifications. The same was true for most MODISA land bands; their SNRs were all significantly higher than the NASA specifications (after adjusting the input radiance to $L_{\text {typical }}$ ) except for the 1640 and $2130 \mathrm{~nm}$ bands. For example, at $859 \mathrm{~nm}$, the NASAspecified SNR was 201 with an input radiance of $2.47 \mathrm{~mW} \mathrm{~cm}^{-2} \mu \mathrm{m}^{-1} \mathrm{sr}^{-1}$, but our estimates showed an SNR of 157.4 at a much lower input radiance of $0.40 \mathrm{~mW} \mathrm{~cm}{ }^{-2} \mu \mathrm{m}^{-1} \mathrm{sr}^{-1}$. If the input radiance was adjusted from 2.47 to $0.40 \mathrm{~mW} \mathrm{~cm}^{-2} \mu \mathrm{m}^{-1} \mathrm{sr}^{-1}$, the NASA SNR specification for this band would be 80.9, much lower than 157.4 from our calculations. At $555 \mathrm{~nm}$ where $L_{\text {typical }}$ was similar to the NASA specifications, the SNR was higher than that estimated from the solar diffuser measurements at a similar input radiance (Fig. 4 of [9]). For similar wavelengths, the SNRs of the land bands were much lower than those of the ocean bands. If these higherresolution $(250$ and $500 \mathrm{~m}$ ) land bands are aggregated to the same resolution as the ocean bands $(1 \mathrm{~km})$, their SNRs can increase significantly (e.g., compare SNRs of MERIS-FR and MERIS-RR data in Table $\underline{7}$ ).

These results from MODISA estimates do not always agree with those reported in Franz et al. [11], even though the $L_{\text {typical }}$ input radiances used in both

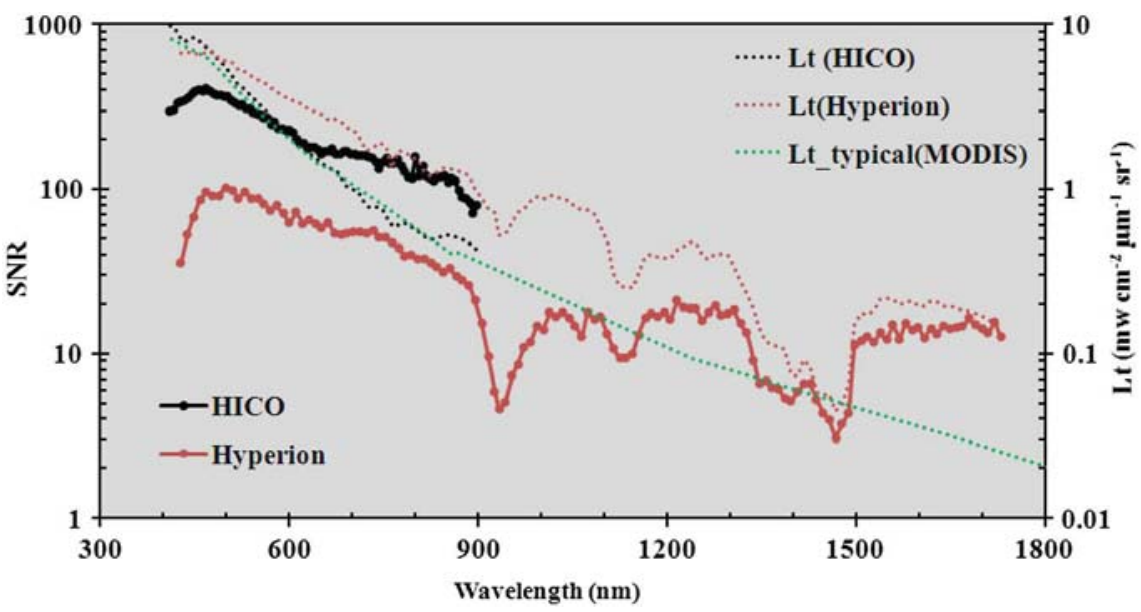

Fig. 8. (Color online) Similar to Fig. 7, but these SNR values were determined from hyperspectral instruments of HICO (black symbols) and Hyperion (brown symbols), respectively. While the input radiance used to determine HICO SNR is similar to $L_{\text {typical }}$ for MODIS (green; the same as $L_{\text {typical }}$ in Fig. 7), the input radiance used to determine Hyperion SNR is higher than MODIS $L_{\text {typical }}$ in the green, red, NIR, and most shortwave IR wavelengths. 
studies are similar. While the SNRs derived here for the blue-green ocean bands $(412-547 \mathrm{~nm})$ are very similar to those of Franz et al. [11], the red (667 and $678 \mathrm{~nm}$ ) and NIR (748 and $869 \mathrm{~nm}$ ) ocean bands showed 20\%-40\% lower SNRs here. In contrast, all the land bands showed higher SNRs than those listed in Franz et al. [11]. We believe that this contrast is because of the different reference targets used in the two evaluations: this study used measured radiances from homogeneous targets as the reference, while Franz et al. [11] used solar-diffuserbased measurements as the reference. Because many sensors are not equipped with solar diffusers, the approach used here should at least provide a consistent evaluation between different sensors.

Next to MODISA and MERIS-RR SNRs is MERISFR in the blue-green bands, followed by SeaWiFS, OCM, and GOCI. For the visible bands, SeaWiFS SNRs all exceeded the prelaunch specifications (Table 7), consistent with the findings from the solar diffuser measurements [10]. However, SeaWiFS SNRs in the NIR bands were lower than the sensor specifications or as found by Barnes et al. [28] and Eplee et al. [10]. They were lower than OCM and GOCI for the same wavelengths. The disproportionally low SNRs in the SeaWiFS NIR bands have significant implications on atmospheric correction $[29,30]$ and ocean color data products, as small noises in these bands would propagate to much higher noises in the blue-green bands through atmospheric correction, resulting in pixelization in Chl images [4].

Compared with MODISA ocean bands and MERIS-RR, MERIS-FR showed considerably lower SNRs for all bands, but most of these FR SNRs agree very well with those reported by Delwart [31]. This is understandable because MERIS-FR at $30 \overline{0} \mathrm{~m}$ resolution collected much less photons than the MERIS-RR data at $1.2 \mathrm{~km}$ resolution. The reduced SNRs for MERIS FR are associated with gains in spatial resolution, important for coastal zone studies. As expected, the proof-of-concept CZCS several decades ago showed significantly lower SNRs than other ocean color sensors. The land-oriented sensors all showed SNRs below 100 for all bands for the typical ocean radiances over nonbright targets, suggesting that special treatment of the data (e.g., spatial binning) may be required when these instruments are used for ocean applications.

One of the most notable results is that although the geostationary GOCI is at an altitude far from the Earth's surface (about 36,000 km versus about $700 \mathrm{~km}$ for a polar-orbiting satellite) with a higher spatial resolution $(500 \mathrm{~m})$ than SeaWiFS $(1 \mathrm{~km})$, SNRs in the visible bands were similar to those of SeaWiFS, and in the NIR were much higher (more than double) than SeaWiFS, because of the longer dwell times possible from a geosynchronous orbit. If GOCI data are binned to $1000 \mathrm{~m}$ resolution, the SNRs will be significantly higher. It is thus expected that GOCI will provide more precise (but not necessarily more accurate) ocean color products than SeaWiFS. This inference has been verified in a preliminary study using only several images [32] but will be tested thoroughly once GOCI data become routinely available.

SNRs of the hyperspectral instruments of HICO and Hyperion were also estimated in the same manner. Because of the limited data availability, the SNR calculations were restricted to input radiance as close to MODISA $L_{\text {typical }}$ as possible, but not exactly the same as with the above calculations. Figure $\underline{8}$ shows the SNRs of HICO and Hyperion at the corresponding input radiances. Note that the HICO input radiance was very similar to MODISA $L_{\text {typical }}$ for all bands, while the Hyperion was designed for land imaging and the input radiance was much higher than MODISA $L_{\text {typical }}$ for wavelengths $>600 \mathrm{~nm}$. For wavelengths $<600 \mathrm{~nm}$, HICO SNRs were $>200$ and reached $>400$ at $500 \mathrm{~nm}$ for the given input radiance. This result agrees well with the sensor specifications
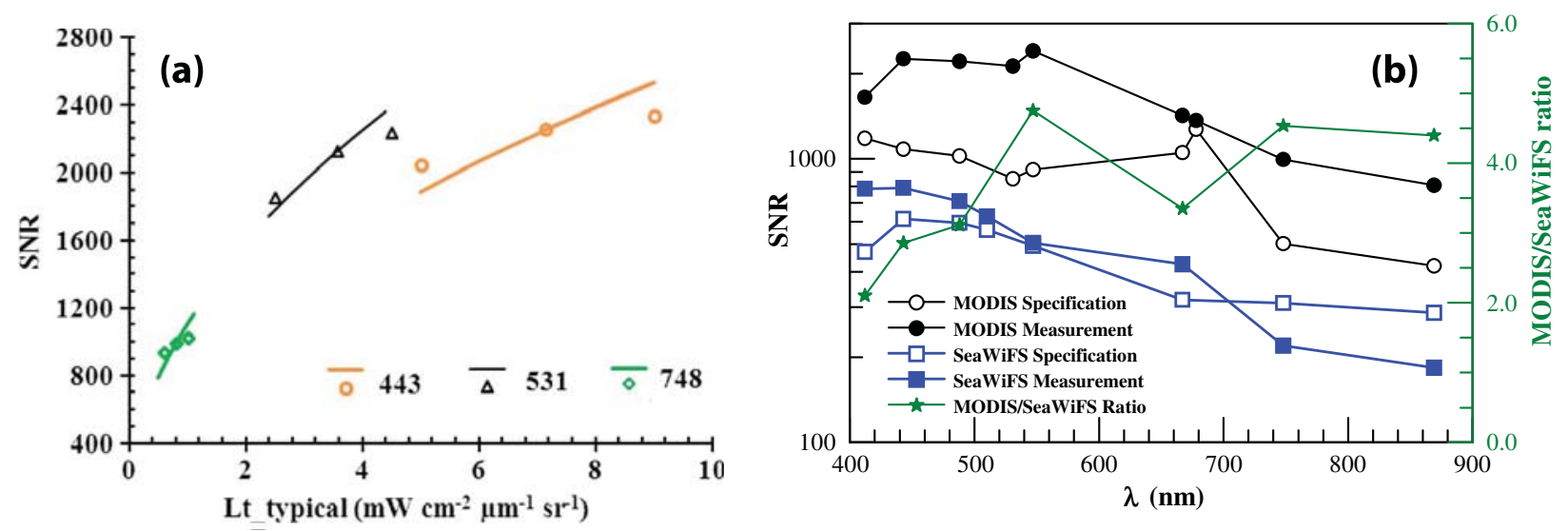

Fig. 9. (Color online) (a) SNR at different radiance $\left(L_{t}\right)$ inputs (solid curves), modeled from SNR at one $L_{t}$ input using a square root function. Also plotted are the SNR values derived at different $\left(L_{t}\right)$ from direct MODISA measurements (discrete symbols); (b) MODISA and SeaWiFS SNRs determined from measurements over the ocean (solid symbols) at input radiance of MODISA $L_{\text {typical }}$ at SZA $=45^{\circ}$. These SNRs are compared with those from the sensor specifications after adjustment of the input radiance to the same $L_{\text {typical }}$ (empty symbols). Also shown in the figure are the MODISA/SeaWiFS SNR ratios (stars) for the same $L_{\text {typical }}$ input radiance. 
[16] and is significantly higher than the Hyperion SNR even if the input radiance of Hyperion is much higher. The result suggests that while HICO can be used for ocean studies at original spectral and spatial resolutions, spectral and/or spatial binning of Hyperion may be required to improve SNRs for the dark ocean.

Except for the hyperspectral sensors, SNRs of all sensors were evaluated in this study at nearidentical input radiance (MODISA $L_{\text {typical }}$ at $\mathrm{SZA}=45^{\circ}$ ) so their performance could be compared with each other directly. On the other hand, to compare them with published SNRs of other sensors at different input radiances, some adjustments are necessary, because SNR depends on the input signal.

Figure 9(a) shows an example using three MODISA ocean bands at 443, 547, and $678 \mathrm{~nm}$. As expected, all SNRs increased with increasing input radiance. Results for other bands were similar. These sensors are designed to be shot-noise limited and therefore the SNR should be proportional to the square root of the input signal. Using this simple model, we can predict the SNR at another input radiance using the SNR at $L_{\text {typical }}\left(\right.$ MODISA, SZA $=45^{\circ}$ ). Figure $\underline{9(\mathrm{a})}$ shows how the predicted SNRs (solid curves) agree with those determined from measurements (symbols) for the three MODISA ocean bands. Comparison of the predicted and measured SNRs showed $<10 \%$ difference for most MODISA bands, with better performance in the visible ocean bands than in the NIR ocean bands and the land bands, possibly due to the higher SNRs in the former. The result suggests that SNR at an arbitrary input radiance, when it is within $\pm 50 \%$ of $L_{\text {typical }}$, can be predicted from the known SNR at $L_{\text {typical }}$, or vice versa, with uncertainties generally $<10 \%$.

This result is also useful when comparing SNRs obtained in this study with other published SNRs at different input radiances. For example, after the SNRs of MODISA and SeaWiFS from the sensor specifications were adjusted to force the input radiance to change from the specifications (Table 4) to MODISA $L_{\text {typical }}$ at $\mathrm{SZA}=45^{\circ}$ using a square root function of radiance [Fig. 9(b), empty symbols], they could be compared directly with those determined from MODISA and SeaWiFS measurements at $L_{\text {typical }}$ [Fig. 9(b), solid symbols]. The NASA SNR specifications after adjustment of the input radiance are listed in Table $\underline{7}$ (bold font in parenthesis). For MODISA, all ocean bands except $678 \mathrm{~nm}$ showed significantly higher SNRs than the sensor specifications (35\%-160\%). Likewise, all SeaWiFS visible bands (except $555 \mathrm{~nm}$ ) showed significantly higher SNRs than the sensor specifications (12\%-67\%), but the NIR bands showed much lower ( $230 \%)$ SNRs than the specifications. Overall, under the same $L_{\text {typical }}$ input radiance, MODISA SNRs are 2.1-4.7 times the SeaWiFS SNRs for the visible bands, and about 4.4 times the SeaWiFS SNRs for the NIR bands.
It has been shown that the performance of the SeaWiFS NIR bands has degraded over the mission span (1997-2010) [10]. However, evaluation of SeaWiFS SNRs using measurements from 1998, 2004, and 2010 resulted in virtually the same SNRs, with their long-term differences smaller than the standard deviations. Thus, the SNRs presented in Table 7 may represent time-independent values for future references.

\section{Impact of SNR on Ocean Color Data Products}

The sensor sensitivity to detect small changes in ocean properties is a direct function of the sensor's SNR. Consistent with the decreasing SNR trend from MODISA to SeaWiFS, the corresponding Chl data products showed increasing pixelization noise (Fig. 1). While the noise could be visualized from the images in Fig. 1, it was quantified using a similar scheme to that for SNR estimates [33]. For a number of images, noise was estimated from all valid pixels (after discarding those associated with various quality control flags) whose $\mathrm{Chl}$ values equaled the predefined Chl $\left(0.01,0.02, \ldots, 0.4 \mathrm{mg} \mathrm{m}^{-3}\right)$. For each $3 \times 3$ window surrounding the qualified pixel, RMS error was estimated. Then, for all qualifying

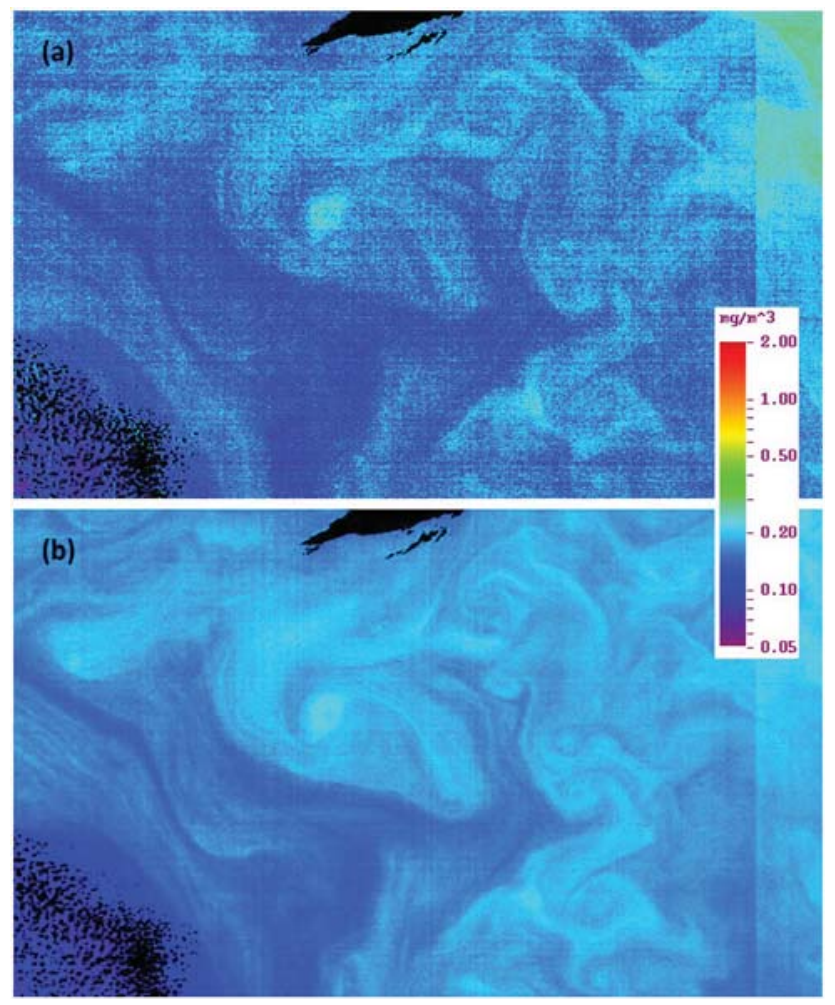

Fig. 10. (Color online) MERIS-FR chlorophyll-a concentrations on 12 March 2009 from a small region in the eastern Gulf of Mexico derived from (a) the default band-ratio OC3 algorithm and (b) a new color index algorithm [33]. Inputs to both algorithms were the spectral $R_{\mathrm{rs}}$ data derived using the atmospheric correction approach in SeaDAS6.3. Note that this is approximately the same region as shown in Fig. 1, but without map projection, so the vertical striping on the right edge is apparent. Note the significant reduction in noise from (a) to (b), where eddy circulation features are clearly revealed. 
windows, the mean of the RMS errors was regarded as a result of the pixelization noise. The ratio between the mean RMS error and the predefined Chl value was used to represent the relative pixelization noise (in percentage). Results are listed in Table 1 . For each predefined Chl, relative noise increased from MODISA to SeaWiFS to MERIS-FR. Relative noises for MERIS-RR Chl were comparable to those of MODISA. For each sensor, relative noise decreased with increasing $\mathrm{Chl}$ and became stable around $0.2-0.4 \mathrm{mg} \mathrm{m}^{-3}$.

Such SNR-related Chl noise has been explained by Hu et al. [4] using both simulations and SeaWiFS observations. Because the atmospheric correction used the NIR bands to determine aerosol type and thickness and then extrapolated to the visible bands, a small error in the NIR, induced by sensor noise or digitization round-off noise, could propagate to the visible bands and become much larger in the resulting water-leaving radiance $\left(L_{w}\right)$ or remote sensing reflectance $\left(R_{\mathrm{rs}}\right)$. The $R_{\mathrm{rs}}$ errors were further propagated in the various products through the bio-optical inversion algorithms. For the blue/green band ratio Chl algorithm [34] that was used in SeaDAS as the default, relative errors in the blue/green ratio depend on the magnitude of the ratio. For oligotrophic oceans with $\mathrm{Chl}<0.1 \mathrm{mg} \mathrm{m}^{3}$, the blue/green ratio could reach 8.0. Thus, a small error in the denominator (green band) would lead to a much larger relative error in the ratio, resulting in larger relative errors in the derived Chl. Other data products (e.g., absorption and backscattering coefficients, attenuation coefficient) may respond differently to the sensor noise, yet the principle is the same, i.e., low sensor SNR will lead to higher noise in the data products.

As demonstrated in the Chl data product for the noise-induced errors, most errors originated from the NIR atmospheric correction bands rather than from the blue-green bands that were used in the bio-optical inversion [4]. This explains why MODISA Chl showed much lower pixelization noise than SeaWiFS Chl (Table 1), as MODISA SNRs in the NIR bands (748 and $8 \overline{69} \mathrm{~nm}$ ) are much higher than SeaWiFS SNRs in the corresponding NIR bands (765 and $865 \mathrm{~nm}$ ). However, the same principle cannot explain why MERIS-FR Chl showed much higher pixelization noise than SeaWiFS Chl or why MERIS-RR Chl showed much higher pixelization noise than MODISA Chl. Because MERIS NIR bands at 754 and $865 \mathrm{~nm}$ have similar SNRs to SeaWiFS SNRs (for MERIS-FR data) and to MODISA SNRs (for MERIS-RR data), one would expect similar performance in the Chl data product derived using the same algorithms, but the results here did not support this expectation. MERIS Chl data obtained from the ESA using similar atmospheric correction and biooptical inversion algorithms but different software (BEAM) showed similar results. It was speculated that this abnormal behavior might be related to the push broom design or the offset stability of MERIS. MERIS has an active offset compensation loop (OCL) to modulate the "effective zero" signal differently across the spectral bands, which will accentuate along-track modulations during atmospheric correction. However, we compared SNRs and Chl pixelization noise estimated from MERIS-RR data during 2010 (OCL-ON) and 2005 (OCL-OFF) and found no difference. Currently the relatively high pixelization noise of MERIS Chl data from such a high-SNR sensor remains a puzzle to be further investigated.

Because the Chl pixelization noise mainly originated from $R_{\mathrm{rs}}$ errors due to imperfect atmospheric correction, once an improved atmospheric correction algorithm is developed to reduce the $R_{\mathrm{rs}}$ errors or a bio-optical inversion algorithm insensitive to the $R_{\mathrm{rs}}$ errors is developed, noise in the product may be significantly reduced. Recently, a band-subtraction color index (CI) algorithm was proposed for Chl retrievals over oligotrophic oceans (Chl $\leq 0.25 \mathrm{mg} \mathrm{m}^{-3}$ ), and the algorithm was proven to be much more tolerant to $R_{\mathrm{rs}}$ errors induced by the imperfect atmospheric correction [33]. Figure 10 shows an example of the improved MERIS-FR Chl product using such a band-subtraction algorithm. Note that the $R_{\text {rs }}$ inputs to the band-ratio algorithm [Fig. 10(a)] and the new band-subtraction algorithm [Fig. 10(b)] were identical, yet the noise in the default band-ratio
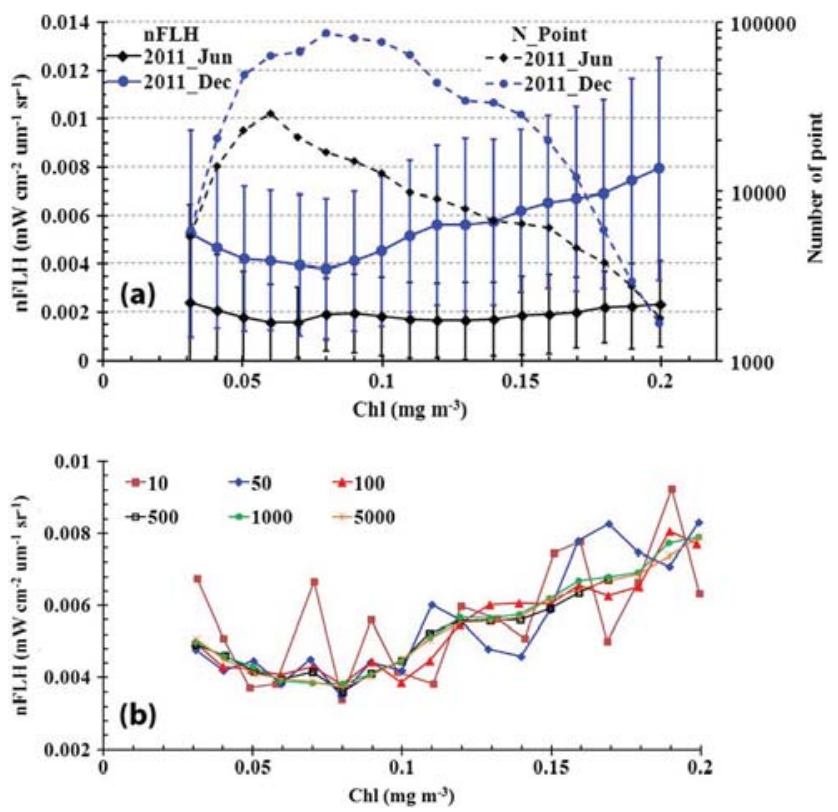

Fig. 11. (Color online) Sensitivity of MODISA normalized FLH (nFLH) in detecting Chl changes at low concentrations. Data were extracted from a $10^{\circ} \times 10^{\circ}\left(60^{\circ}-50^{\circ} \mathrm{W}, 30^{\circ}-40^{\circ} \mathrm{N}\right)$ region near the North Atlantic Gyre. $\mathrm{nFLH}$ was derived from normalized waterleaving radiance at 667, 678, and $748 \mathrm{~nm}$. (a) $\mathrm{nFLH}$ appears to monotonously increase with increasing $\mathrm{Chl}$ for $\mathrm{Chl} \geq$ $0.08 \mathrm{mg} \mathrm{m}^{-3}$ (winter) and for $\mathrm{Chl} \geq 0.14 \mathrm{mg} \mathrm{m}^{-3}$ (summer). $\mathrm{nFLH}$ values are much lower during summer due to nonphotochemical quenching; (b) The sensitivity of $\mathrm{nFLH}$ to resolve small Chl changes is dependent on the number of pixels used in calculating the averages. The annotated numbers indicate the number of pixels used to calculate the mean $\mathrm{nFLH}$ values. It appears that the relationship between $\mathrm{nFLH}$ and $\mathrm{Chl}$ for December 2011 became stabilized for $N \geq 500$. 
Chl has been reduced significantly using the new algorithm. The figure here used MERIS-FR data to show the impact of algorithms on product noise for the same input data. For inter-sensor comparison, the same atmospheric approach implemented in SeaDAS was used to process all ocean color data. If a different approach such as the artificial neural network (ANN) designed for MERIS [35] or other semianalytical inversion algorithms [36-39] were used, the resulting noise in the $\mathrm{Chl}$ products could be significantly lower.

For sensors with a finite dynamic signal range, there is always a trade between SNR (sensitivity) and saturation radiance. It is typical that the SNR for one or two bands drives the sensor design. In the MODIS case the high SNR required for the FLH bands drove the MODIS design; the telescope and other optical components were scaled to achieve the desired SNRs for those bands and, in doing so, all other bands had excess SNRs (e.g., significantly higher than 1000 for the blue-green bands; see Table 7). To maximize the SNR for open ocean scenes, the saturation level was lowered. This often resulted in signal saturation in the FLH and atmospheric correction bands over river plumes, intense algal blooms, or thick aerosols (e.g., Fig. 2), providing no usable data for those regions. Even so, at the current sensor sensitivity MODISA FLH could not resolve $\mathrm{Chl}$ fluorescence changes at low $\mathrm{Chl}$ concentrations from individual images.

An example is shown in Fig. 11 for the North Atlantic. For December 2011, even after averaging $>10,000$ Level-2 $1 \mathrm{~km}$ pixels, normalized FLH ( $\mathrm{nFLH}$ ) could only resolve Chl down to $0.08 \mathrm{mg} \mathrm{m}^{-3}$. Averaging more pixels, especially after extensive binning in both space and time such as in Behrenfeld et al. [40], may further resolve $\mathrm{Chl}$ to about $0.05-0.0 \overline{6 m g ~ m}{ }^{-3}$, yet the large $\mathrm{nFLH}$ variance for a given Chl value [STD bars in Fig. 11(a)] indicated that on individual images the ability of nFLH to resolve low Chl variations was significantly degraded. This was confirmed by comparison between individual nFLH and Chl images (not shown here) and by the sensitivity test in Fig. 11(b), where the nFLH versus Chl relationship became stabilized only after averaging $>500$ pixels. This ability further decreases during summer due to nonphotochemical quenching of the fluorescence efficiency (black symbols in Fig. 11(a); also see Behrenfeld et al. [40]). The current MODISA SNRs appeared sufficient to derive nFLH for studying phytoplankton physiology in the global ocean at large spatial-temporal scales, because many data points could be averaged to increase its sensitivity [40], yet for individual images at original resolution $(1 \mathrm{~km})$, increasing the SNRs in the FLH bands while maintaining a sufficient signal dynamic range for a variety of water types may be a technical challenge for future ocean color sensors. Such capability is particularly important for detecting and quantifying blooms in optically complex waters [41]. Indeed, the noise level in the MODIS nFLH data, as measured by the standard deviation term in Fig. 11(a) for the December 2011 case, is about $0.003-0.004 \mathrm{~mW} \mathrm{~cm}^{-2} \mu \mathrm{m}^{-1} \mathrm{sr}^{-1}$, corresponding to a Chl change of $\sim 0.1 \mathrm{mg} \mathrm{m}^{-3}$ [i.e., from 0.1 to $0.2 \mathrm{mg} \mathrm{m}^{-3}$ in Fig. 11(a)]. Thus, on individual images, current MODIS SNRs cannot resolve $\mathrm{nFLH}$ changes corresponding to $\mathrm{Chl}$ changes of $0.1 \mathrm{mg} \mathrm{m}^{-3}$ when the default FLH algorithm [5] is used. An alternative algorithm based on radiative transfer theory [42] may improve such nFLH sensitivity in detecting Chl changes.

In summary, low sensor SNRs would lead to higher data product noise. The atmospheric correction bands in the NIR play a dominant role in propagating sensor noise to the visible bands and data products through atmospheric correction [4,43], and thus should be emphasized in sensor design. Finally, noise in the current data products can be reduced with improved algorithms even when the sensor's SNRs remain the same.

\section{Discussion}

\section{A. Estimation of SNR from Satellite Measurements}

One objective of the SNR assessment in this study was to put all sensors under the same reference input radiance from realistic measurements so they could be compared directly. The approach used in calculating the SNRs, as detailed in Subsection 4.A, was adapted from a community-accepted method but adjusted using an objective method to restrict to ocean targets as homogeneous as possible through the use of $\mathrm{max} / \mathrm{min}$ ratio thresholds. This is certainly not the only way to calculate SNR. An alternative approach could use extrapolation rather than max/min ratio. To evaluate whether different approaches could result in similar results as shown in Table 7, an extrapolation-based method was implemented and tested. In this method, the criteria to select clear-water pixels $\left(\mathrm{Chl}<0.07 \mathrm{mg} \mathrm{m}^{-3}\right)$ under $L_{\text {typical }}$ were identical to those used in Subsection 4.A. For each of the 20 MODISA images, SNRs for a band were calculated for different window sizes ranging between $2 \times 2$ and $7 \times 7$. The mean SNR of the 20 images for a window size was regarded as the SNR for that window size. An extrapolation of the mean, as a function of window size, to the window size $1 \times 1$ was regarded as the sensor SNR. Such extrapolation-derived MODISA SNRs are comparable to those shown in Table 7 to within $20 \%$, suggesting that both methods could $\bar{b}$ e used to determine sensor SNRs. However, the standard deviations of the mean SNRs (i.e., variability of SNRs across individual images) from this alternative approach were significantly higher than the method (Fig. 5) used to derive Table 7, indicating that the alternative method depends heavily on the selection of the image. Thus, the general consistency between the two independent methods and the significantly lower cross-image variability in the former method suggest that the results listed in Table $\underline{7}$ could be used as valid references to compare 
sensor specifications and performances, and the same method could be used for other or future sensor evaluations to ensure consistency.

\section{B. Other Factors Affecting SNRs}

Instrument engineering teams have found various approaches to meeting SNR specifications, some of which can introduce data artifacts that are not included in the SNR evaluations here. For instance, MODIS used 10 detectors along the track to ensure sufficient dwell time to achieve the desired SNRs, i.e., slow scan rates. This introduced cross-track striping due to residual calibration errors between detectors. Similarly, push broom sensors such as MERIS employed multiple detectors across the track, which resulted in along-track striping errors. In the SNR calculations, these errors were excluded by using the max/min threshold approach (Fig. 5), for otherwise realistic variations in the ocean and/or atmosphere would have been regarded as noise. The striping noise represents a significant error source for many sensors (MODIS, MERIS, Landsat, etc.) that has not been addressed in this paper because it is primarily a cross-detector calibration problem. SeaWiFS avoided this problem by using four detectors in a time-delay-integration scheme but had to spin the telescope at a faster rate. Its bilinear gain, separated at the knee value, was implemented to account for both high sensitivity at low radiance and high saturation levels for land and atmosphere applications.

The assessment did not attempt to differentiate whether the noise originated from the instrumentinherent noise [Eqs. (1) and (2)] or from digitization round-off noise, with the latter determined by the number of digitization bits and the maximum radiance. In practice, to maximize sensor performance, one digital number is often set to be equivalent to the instrument-inherent noise or $\mathrm{NE} \Delta L$, because there is no reason to digitize noise or keep the noise way below the digitization round-off error. Thus, the results presented here represent the image-based evaluations of the SNRs of many sensors under similar radiance inputs over relatively homogeneous waters without differentiating the noise sources.

\section{Implications for GEO-CAPE, PACE, and Other Future Missions}

The ultimate goal of this study was to use past and current ocean color sensors as references to help design future ocean color missions including GEO$\mathrm{CAPE}$ and PACE. From the results and discussions above, substantial experience and lessons have been learned from the past, including the following.

(1) MODISA $L_{\text {typical }}$ values at SZA $=45^{\circ}$ are often different from previous sensor specifications. They also change with different SZAs.

(2) MODISA is much more sensitive (higher SNRs) than SeaWiFS, yet the low saturation radi- ance in the red and NIR bands sometimes resulted in saturation even over cloud-free ocean scenes.

(3) Both MODISA and SeaWiFS showed higher SNRs than prelaunch specifications for most spectral bands.

(4) It is critical to have sufficient SNRs in the atmospheric correction bands. In contrast, the SNR requirements on the visible bands can be relaxed.

(5) Noise in the current data products is primarily due to the algorithmic approach. Improved algorithms can lead to significantly reduced product noise and significantly enhanced product precision.

GEO-CAPE is a geostationary mission with recommended hyperspectral sensor specifications spanning from the UV $(350 \mathrm{~nm})$ to the shortwave IR $(2130 \mathrm{~nm})$. One of the advantages of geostationary sensors is their ability to start to achieve the integration time required to meet the SNR requirements. A primary measurement goal of GEO-CAPE is to quantify short-term changes in ocean properties from early morning to late afternoon when SZA is $\leq 70^{\circ}$. The $L_{\text {typical }}$ values at various SZAs, as listed in Table 4, can serve as references for GEO-CAPE SNR specifications. Likewise, the $L_{\max }$ values listed in Tables 5 and 6 at various SZAs can serve as references to determine the saturation radiance and sensor integration time under various measurement scenarios. Although Table 6 is preferred, the difference between $L_{\max }$ for the $5 \%$ and $1 \%$ brightest pixels provides a reference for the trade space between sensitivity and saturation. Note that these $L_{\text {typical }}$ and $L_{\max }$ values were determined using MODISA multiband measurements. For hyperspectral sensors, $L_{\text {typical }}$ and $L_{\max }$ at other wavelengths can be derived from the tables using interpolation and extrapolation and using the extraterrestrial solar irradiance as a reference.

It is clear that MODISA SNRs are sufficient to resolve very small changes $(<10 \%)$ even at extremely low Chl concentrations ( $0.03 \mathrm{mg} \mathrm{m}^{-1}$; Table 1 ). When the new band-subtraction algorithm was used, the sensitivity was even higher to resolve changes of $<5 \%$ for Chl between 0.01 and $0.4 \mathrm{mg} \mathrm{m}^{-3}$ ([33]; Fig. 10). Thus, MODISA SNRs can be used as a template to define GEO-CAPE specifications. Because it is important to be able to detect small changes during early morning and late afternoon at $\mathrm{SZA}=70^{\circ}$, SNRs should be defined at this SZA.

Based on the MODISA results shown here, and based on the radiative transfer simulations of Wang [43], we believe that the following SNRs should provide sufficient sensitivity for the GEO-CAPE mission: $>1000$ for $\lambda$ between 350 and $720 \mathrm{~nm},>600$ for 720-900 nm, and >100-200 for the shortwave infrared (SWIR) bands. For all spectral bands, saturation levels should be set to or interpolated from those listed in Tables $\underline{5}$ and $\underline{6}$, which will avoid saturation over land and all but the brightest clouds. The simulations of Wang [43] considered two cases for maritime and tropospheric aerosols with an aerosol 
optical thickness at $865 \mathrm{~nm}$ of up to 0.2 , where the SNR requirement was estimated to be slightly lower than listed above. Note that these recommended SNRs are much lower in the visible and slightly lower in the NIR, but significantly higher in the SWIR when compared with MODISA SNRs determined from $L_{\text {typical }}$ at SZA $=45^{\circ}$ (Table 7 ). Because most noise in the data products results from the atmospheric correction bands in the NIR and SWIR as opposed to the blue-green bands [4,43], the performance of GEO-CAPE in resolving small changes in ocean properties should be at least comparable to that of MODISA if the same atmospheric and biooptical inversion approaches are used with the NIR bands. If SWIR bands are used for atmospheric correction of both MODISA and GEO-CAPE, significantly improved performance should be achieved from GEO-CAPE over MODISA because of the increased SNRs in the SWIR bands.

Of particular interest for GEO-CAPE is the ability to derive changes in chlorophyll-a fluorescence quantum yield with repeated diurnal measurements. Can GEO-CAPE with similar SNRs to MODISA resolve such changes? Morrison [44] showed that when the surface photosynthetically available radiation (PAR; $\mu$ mole photons $\mathrm{m}^{-2} \mathrm{~s}^{-1}$ ) changed from 1000 to 600 (corresponding to $\mathrm{SZA}=60^{\circ}$ and $70^{\circ}$, respectively), the fluorescence quantum yield nearly doubled (Fig. 9 of [44]). For waters with $\mathrm{Chl}=0.15 \mathrm{mg} \mathrm{m}^{-3}$, this quantum yield change would result in $\mathrm{nFLH}$ changes of $\sim 0.004 \mathrm{~mW} \mathrm{~cm}^{-2} \mu \mathrm{m}^{-1} \mathrm{sr}^{-1}$ [Fig. 11(a)], distinguishable from the background noise level [0.0030.004; see standard deviation in Fig. 11(a)]. This estimate is based on individual images. If the Chl is higher, or if many pixels are averaged for these low-concentration waters, smaller changes in fluorescence quantum yield can also be quantified with the current MODISA SNRs and the default algorithms.

\section{Conclusion}

The trade space between sensor SNR (or sensitivity) and dynamic range (or saturation radiance) needs to be determined carefully in order to quantify small changes of ocean properties (e.g., Chl) under most measurement scenarios. Using measurements of MODISA and other ocean color sensors together with a new objective method, typical ( $\left.L_{\text {typical }}\right)$ and maximum $\left(L_{\max }\right)$ at-sensor radiances were determined under different SZAs, with SNRs determined from uniform ocean targets at the same input radiance as $L_{\text {typical }}$. These results make it possible for the first time to have direct cross-sensor comparisons of SNRs under the same measurement conditions. The tabulated results also serve as references to compare with other existing sensors and to help design future sensors such as the geostationary GEO-CAPE or the polar-orbiting PACE.

This work was supported by the state of Florida, the U.S. NASA Ocean Biology and Biogeochemistry (OBB) program and the Water and Energy Cycle program and inspired by numerous discussions within the GEO-CAPE science definition team. Support of L. Fenghas been provided by an education program for visiting and exchanging students. We thank the various agencies that provided satellite data in this study, including the NASA Goddard Space Flight Center, U.S. Geological Survey, the European Space Agency, the Earth Scan Lab of Louisiana University, Oregon State University, and Korea Ocean Research and Development Institute (KORDI). The authors thank Drs. M. Behrenfeld and T. Westberry (Oregon State University) for their helpful discussions on MODIS FLH data products. The manuscript benefited from substantial comments and suggestions provided by three anonymous reviewers, whose contribution is acknowledged.

\section{References}

1. J. Fishman, J. Al-Saadi, P., Bontempi, K. Chance, F. Chavez, M. Chin, P. Coble, C. Davis, P. DiGiacomo, A. Eldering, D. Edwards, J. Goes, J. Herman, C. Hu, L. Iraci, D. Jacob, C. Jordan, S. R. Kawa, R. Key, X. Liu, S. Lohrenz, A. Mannino, V. Natraj, D. Neil, J. Neu, M. Newchurch, K. Pickering, J. Salisbury, H. Sosik, A. Subramaniam, M. Tzortziou, J. Wang, M. Wang, GEO-CAPE Atmospheric Science Working Group, and GEO-CAPE Ocean Science Working Group, "Fulfilling the mandate and meeting the challenges of the nation's next generation of atmospheric composition and coastal ecosystem measurements: NASA's Geostationary Coastal and Air Pollution Events (GEO-CAPE) mission," Bull. Am. Meterol. Soc. (to be published).

2. National Research Council, Earth Science and Applications from Space: National Imperatives for the Next Decade and Beyond. Committee on Earth Science and Applications from Space: A Community Assessment and Strategy for the Future (National Academic Press, 2007) (http://www.nap.edu/catalog/ 11820.html).

3. National Aeronautics and Space Administration, "Responding to the challenge of climate and environmental change: NASA's plan for a climate-centric architecture for Earth observations and applications from space" (NASA, 2010) (http://science .nasa.gov/earth-science/).

4. C. Hu, K. L. Carder, and F. E. Muller-Karger, "How precise are SeaWiFS ocean color estimates? Implications of digitization-noise errors," Remote Sens. Environ. 76, 239-249 (2001).

5. R. M. Letelier and M. R. Abbott, "An analysis of chlorophyll fluorescence algorithms for the moderate resolution imaging spectrometer (MODIS)," Remote Sens. Environ. 58, 215-223 (1996).

6. http://suzaku.eorc.jaxa.jp/GLI/ov/spec_table.html.

7. T. Y. Nakajima, T. Nakajima, M. Nakajima, H. Fukushima, M. Kuji, A. Uchiyama, and M. Kishino, "Optimization of the Advanced Earth Observing Satellite II Global Imager channels by use of radiative transfer calculations," Appl. Opt. 37, 3149-3163 (1998).

8. International Ocean-Colour Coordinating Group, "Minimum requirements for an operational, ocean-colour sensor for the open ocean," IOCCG Report Number 1 (International Ocean-Colour Coordinating Group, 1998).

9. X. Xiong, A. Angal, and X. Xie, "On-orbit noise characterization for MODIS reflective solar bands," in Proceedings of the IEEE International Geoscience and Remote Sensing Symposium, 2008 (IEEE, 2008).

10. J. R. E. Eplee, F. S. Patt, R. A. Barnes, and C. R. McClain, "SeaWiFS long-term solar diffuser reflectance and sensor noise analyses," Appl. Opt. 46, 762-773 (2007).

11. B. A. Franz, P. J. Werdell, G. Meister, E. J. Kwiatkowska, S. W. B. Z. Ahmad, and C. R. McClain, "MODIS land bands for ocean remote sensing applications," presented at Ocean Optics XVIII, Montreal, Canada, 9-13 October 2006, http:// 
oceancolor.gsfc.nasa.gov/staff/franz/papers/franz_et_al_2006_ oo.pdf.

12. C. Giardino, V. E. Brando, A. G. Dekker, N. Strömbeck, and G. Candiani, "Assessment of water quality in Lake Garda(Italy) using Hyperion,” Remote Sens. Environ. 109, 183-195 (2007).

13. Z. Lee, B. Casey, R. Arnone, A. Weidemann, R. Parsons, M. J. Montes, B.-C. Gao, W. Goode, C. Davis, and J. Dye, "Water and bottom properties of a coastal environment derived from Hyperion data measured from the EO-1 spacecraft platform," J. Appl. Remote Sens. 1, 011502 (2007).

14. R. K. Vincent, X. Qin, R. M. L. McKay, J. Miner, K. Czajkowski, J. Savino, and T. Bridgeman, "Phycocyanin detection from LANDSAT TM data for mapping cyanobacterial blooms in Lake Erie," Remote Sens. Environ. 89, 381-392 (2004).

15. Z. Yu, X. Chen, B. Zhou, L. Tian, X. Yuan, and L. Feng, "Assessment of total suspended sediment concentrations in Poyang Lake using HJ-1A/1B CCD imagery," Chin. J. Oceanol. Limnol. 30, 295-304 (2012).

16. R. L. Lucke, M. Corson, N. R. McGlothlin, S. D. Butcher, D. L. Wood, D. R. Korwan, R. R. Li, W. A. Snyder, C. O. Davis, and D. T. Chen, "Hyperspectral Imager for the Coastal Ocean: instrument description and first images," Appl. Opt. 50, 1501-1516 (2011)

17. http://glovis.usgs.gov.

18. http://hico.coas.oregonstate.edu.

19. Information sources (accessed on 19 January 2012): MODIS: http://modis.gsfc.nasa.gov/about/specifications.php; MERIS: http://envisat.esa.int/earth/www/object/index.cfm?fobjectid= 1665\&contentid=3744; SeaWiFS: http://oceancolor.gsfc.nasa .gov/SeaWiFS/SEASTAR/SPACECRAFT.html; OCM: http:// www.isro.org/satellites/irs-p4_oceansat.aspx; GOCI: http:// kosc.kordi.re.kr/oceansatellite/coms-goci/specification.kosc; CZCS: http://oceancolor.gsfc.nasa.gov/CZCS/czcs_instrument .html; Landsat7 ETM+: http://landsat.gsfc.nasa.gov/about/ etm+.html; Landsat5 TM: http://landsat.gsfc.nasa.gov/about/ tm.html; HJ-CCD: http://www.cresda.com/n16/n1130/n1582/ 8384.html; GOES/Imager: http://www.class.ncdc.noaa.gov/ release/data_available/goes/index.htm; HICO: http://hico .coas.oregonstate.edu; Hyperion: http://edcsns17.cr.usgs.gov/ eo1/sensors/hyperion.

20. R. D. Fiete and T. Tantalo, "Comparison of SNR image quality metrics for remote sensing systems," Opt. Eng. 40, 574-585 (2001).

21. W. J. Moses, J. H. Bowles, R. L. Lucke, and M. R. Corson, "Impact of signal-to-noise ratio in a hyperspectral sensor on the accuracy of biophysical parameter estimation in case II waters," Opt. Express 20, 4309-4330 (2012).

22. P. J. Curran and J. L. Dungan, "Estimation of signal-to-noise: a new procedure applied to AVIRIS data," IEEE Trans. Geosci. Remote Sens. 27, 620-628 (1989).

23. B.-C. Gao, "An operational method for estimating signal to noise ratios from data acquired with imaging spectrometers," Remote Sens. Environ. 43, 23-33 (1993).

24. R. O. Green, B. E. Pavri, and T. G. Chrien, "On-orbit radiometric and spectral calibration characteristics of EO-1 Hyperion derived with an underflight of AVIRIS and in situ measurements at Salar de Arizaro, Argentina," IEEE Trans. Geosci. Remote Sens. 41, 1194-1203 (2003).

25. F. A. Kruse, J. W. Boardman, and J. F. Huntington, "Comparison of airborne hyperspectral data and EO-1 Hyperion for mineral mapping," IEEE Trans. Geosci. Remote Sens. 41, 1388-1400 (2003).

26. M. Wettle, V. E. Brando, and A. G. Dekker, "A methodology for retrieval of environmental noise equivalent spectra applied to four Hyperion scenes of the same tropical coral reef," Remote Sens. Environ. 93, 188-197 (2004).

27. C. R. McClain, S. R. Signorini, and J. R. Christian, "Subtropical gyre variability observed by ocean-color satellites," Deep Sea Research II: Top. Stud. Oceanogr. 51, 281-301 (2004).

28. R. A. Barnes, W. L. Barnes, W. E. Esaias, and C. R. McClain, "Prelaunch Acceptance report for the SeaWiFS radiometer," NASA Technical Memo 104566, S. B. Hooker, E. R. Firestone, and J. G. Acker, eds. (NASA Goddard Space Flight Center, 1994), Vol. 22
29. H. R. Gordon, "Atmospheric correction of ocean color imagery in the Earth Observing System era," J. Geophys. Res. 102, 17081-17106 (1997).

30. H. R. Gordon and M. Wang, "Retrieval of water-leaving radiance and aerosol optical thickness over the oceans with SeaWiFS: a preliminary algorithm," Appl. Opt. 33, 443-452 (1994).

31. S. Delwart, "MERIS US workshop: instrument characterization overview," presented at ESA/MERIS Workshop, OCEANS.US Office, Silver Spring, Md., USA, 14 July 2008 (http:/oceancolor.gsfc.nasa.gov/MEETINGS/ESA_MERIS/ presentations/InstCharacOverview.pdf).

32. C. Hu, F. Lian, and Z. Lee, "Evaluation of GOCI sensitivity for at-sensor radiance and GDPS-retrieved chlorophyll-a products," submitted to Ocean Science J..

33. C. Hu, Z. Lee, and B. Franz, "Chlorophyll a algorithms for oligotrophic oceans: a novel approach based on threeband reflectance difference," J. Geophys. Res. 117, C01011 (2012).

34. J. E. O'Reilly, S. Maritorena, M. O’Brien, D. Siegal, D. Toole, D. Menzies, R. Smith, J. Mueller, B. Mitchell, S. Hooker, C. McClain, K. Carder, F. Müller-Karger, M. Kahru, F. Chavez P. Strutton, G. Cota, L. Harding, A. Magnuson, D. Phinney, G. Moore, J. Aiken, K. Arrigo, R. Letelier, and M. Culver, "SeaWiFS Postlaunch Calibration and Validation Analyses, Part 3," in NASA Technical Memorandum 2000-206892 SeaWiFS Postlaunch Technical Report Series, S. Hooker and E. Firestone, eds. (NASA Goddard Space Flight Center, 2000), Vol. 11.

35. T. Schroeder, I. Behnert, M. Schaale, J. Fischer, and R. Doerffer, "Atmospheric correction algorithm for MERIS above case-2 waters," Int. J. Remote Sens. 28, 1469-1486 (2007).

36. K. L. Carder, F. R. Chen, Z. P. Lee, S. K. Hawes, and D. Kamykowski, "Semianalytic Moderate-Resolution Imaging Spectrometer algorithms for chlorophyll a and absorption with bio-optical domains based on nitrate-depletion temperatures," J. Geophys. Res. 104, 5403-5421 (1999).

37. Z. Lee, K. L. Carder, and R. A. Arnone, "Deriving inherent optical properties from water color: a multiband quasi-analytical algorithm for optically deep waters," Appl. Opt. 41, 5755-5772 (2002).

38. S. Maritorena, D. A. Siegel, and A. R. Peterson, "Optimization of a semianalytical ocean color model for global-scale applications," Appl. Opt. 41, 2705-2714 (2002).

39. S. Sathyendranath, L. Prieur, and A. Morel, "A three component model of ocean colour and its application to remote sensing of phytoplankton pigments in coastal waters," Int. J. Remote Sens. 10, 1373-1394 (1989)

40. M. J. Behrenfeld, T. K. Westberry, E. S. Boss, R. T. O’Malley, D. A. Siegel, J. D. Wiggert, B. A. Franz, C. R. McClain, G. C. Feldman, S. C. Doney, J. K. Moore, G. Dall'Olmo, A. J. Milligan, I. Lima, and N. Mahowald, "Satellite-detected fluorescence reveals global physiology of ocean phytoplankton," Biogeosci. Discuss. 5, 4235-4270 (2008).

41. C. Hu, F. E. Muller-Karger, C. Taylor, K. L. Carder, C. Kelble, E. Johns, and C. A. Heil, "Red tide detection and tracing using MODIS fluorescence data: a regional example in SW Florida coastal waters," Remote Sens. Environ. 97, 311-321 (2005).

42. Y. Huot, C. A. Brown, and J. J. Cullen, "New algorithms for MODIS sun-induced chlorophyll fluorescence and a comparison with present data products," Limnol. Oceanogr.: Methods 3, 108-130 (2005).

43. M. Wang, "Remote sensing of the ocean contributions from ultraviolet to near-infrared using the shortwave infrared bands: simulations," Appl. Opt. 46, 1535-1547 (2007).

44. J. R. Morrison, "In situ determination of the quantum yield of phytoplankton chlorophyll a fluorescence: a simple algorithm, observations, and a model," Limnol. Oceanogr. 48, 618-631 (2003).

45. S. B. Hooker, E. R. Firestone, W. E. Esaias, G. C. Feldman, W. W. Gregg, and C. R. McClain, "An overview of SeaWiFS and ocean color," NASA Technical Memorandum, S. B. Hooker and E. R. Firestone, eds. (NASA Goddard Space Flight Center, 1992). 